\title{
Crosstalk between endoplasmic reticulum stress and oxidative stress: a dynamic duo in multiple myeloma
}

\author{
Sinan Xiong ${ }^{1} \cdot$ Wee-Joo Chng $^{1,2,3} \cdot$ Jianbiao Zhou ${ }^{1,2} \mathbb{D}$
}

Received: 29 August 2020 / Revised: 19 December 2020 / Accepted: 5 January 2021 / Published online: 18 February 2021

(c) The Author(s) 2021

\begin{abstract}
Under physiological and pathological conditions, cells activate the unfolded protein response (UPR) to deal with the accumulation of unfolded or misfolded proteins in the endoplasmic reticulum. Multiple myeloma (MM) is a hematological malignancy arising from immunoglobulin-secreting plasma cells. MM cells are subject to continual ER stress and highly dependent on the UPR signaling activation due to overproduction of paraproteins. Mounting evidence suggests the close linkage between ER stress and oxidative stress, demonstrated by overlapping signaling pathways and inter-organelle communication pivotal to cell fate decision. Imbalance of intracellular homeostasis can lead to deranged control of cellular functions and engage apoptosis due to mutual activation between ER stress and reactive oxygen species generation through a self-perpetuating cycle. Here, we present accumulating evidence showing the interactive roles of redox homeostasis and proteostasis in MM pathogenesis and drug resistance, which would be helpful in elucidating the still underdefined molecular pathways linking ER stress and oxidative stress in MM. Lastly, we highlight future research directions in the development of anti-myeloma therapy, focusing particularly on targeting redox signaling and ER stress responses.
\end{abstract}

Keywords Multiple myeloma $\cdot$ Endoplasmic reticulum stress $\cdot$ Oxidative stress $\cdot$ Reactive oxygen species $\cdot$ Unfolded protein response

Abbreviations
AKT
AML
ASK1
ATF6
BCR
BiP
CHOP

Activation of protein kinase B

Acute myeloid leukemia

Apoptosis signal-regulating kinase 1

Activating transcription factor 6

B-cell antigen receptor

Binding immunoglobulin protein

C/EBP-homologous protein

Wee-Joo Chng

mdccwj@nus.edu.sg

Jianbiao Zhou

csizjb@nus.edu.sg

1 Department of Medicine, Yong Loo Lin School of Medicine, National University of Singapore, Singapore 117597, Republic of Singapore

2 Centre for Translational Medicine, Cancer Science Institute of Singapore, National University of Singapore, 14 Medical Drive, Singapore 117599, Republic of Singapore

3 Department of Hematology-Oncology, National University Cancer Institute of Singapore (NCIS), The National University Health System (NUHS), 1E, Kent Ridge Road, Singapore 119228, Republic of Singapore

$\begin{array}{ll}\text { CHOP/GADD153 } & \text { C/EBP-homologous protein } \\ \text { DUOX } & \text { Dual oxidase } \\ \text { eIF2 } \alpha & \text { Eukaryotic initiation factor-2 } \alpha \\ \text { ER } & \text { Endoplasmic reticulum } \\ \text { ERAD } & \text { ER-associated degradation } \\ \text { ERO1 } & \begin{array}{l}\text { Endoplasmic reticulum } \\ \text { oxidoreductin-1 }\end{array} \\ \text { GSH } & \text { Glutathione } \\ \text { HIF } & \text { Hypoxia-inducible factor } \\ \text { IRE1 } \alpha & \text { Inositol requiring kinase 1 } \alpha \\ \text { JNK } & \text { C-Jun N-terminal kinase } \\ \text { MAM } & \text { Mitochondria-associated ER } \\ & \text { membrane } \\ \text { MGUS } & \text { Monoclonal gammopathy of undeter- } \\ & \text { mined significance } \\ \text { MM } & \text { Multiple myeloma } \\ \text { mTORC1 } & \text { Rapamycin complex 1 } \\ \text { NF- } \kappa \text { B } & \text { Nuclear factor- } \kappa B \\ \text { NOX } & \text { NADPH oxidase } \\ \text { Nrf2 } & \text { BZIP Cap 'n' Collar transcription } \\ & \text { factor } \\ \text { PDI } & \text { Protein disulfide isomerase }\end{array}$




$\begin{array}{ll}\text { PERK } & \begin{array}{l}\text { Double-stranded RNA-activated } \\ \text { protein kinase-like ER kinase }\end{array} \\ \text { PI3K } & \text { Phosphoinositide 3-kinase } \\ \text { PRX } & \text { Peroxiredoxin } \\ \text { ROS } & \text { Reactive oxygen species } \\ \text { SMM } & \text { Smoldering myeloma } \\ \text { SOD } & \text { Superoxide dismutase } \\ \text { Trx } & \text { Thioredoxin } \\ \text { TrxR } & \text { Thioredoxin reductase } \\ \text { UPR } & \text { Unfolded protein response } \\ \text { XBP1 } & \text { X-box Binding Protein }\end{array}$

\section{Introduction}

Multiple myeloma (MM) is a genetically complex and heterogeneous hematologic malignancy with an estimated worldwide 5 year prevalence of around 230,000 individuals [1]. It is characterized by malignant proliferation of highly secretory monoclonal plasma cells in the bone marrow. $\mathrm{MM}$ is a progressive disease, which is usually preceded by premalignant asymptomatic conditions, monoclonal gammopathy of undetermined significance (MGUS) or smoldering myeloma (SMM). Despite recent advancement in stem-cell transplantation, high-dose chemotherapy and novel therapies, MM remains an incurable disease with an overall 5 year survival rate of approximately 53.9\% from 2010 to 2016 [2]. Most myeloma patients experience relapses that require additional therapies, underscoring the urgent need to understand the mechanistic drivers of therapeutic resistance to develop better interventions.

The accurate and durable maintenance of functional cellular proteome requires an intricate regulation of the protein homeostasis (proteostasis) network and has been associated with aging and diseases [3]. Very mild perturbation of proteostatic fine-tuning and related stress-response pathways can be sufficient to impact not only a myriad of cellular functions but also tissue integrity [4]. Extensive protein synthesis in MM cells is accompanied by adaptive alterations in metabolic pathways [5], and accumulation of unfolded or misfolded protein in the ER lumen that triggers unfolded protein response (UPR) to resolve ER stress and restore proper protein folding.

Secretory cells like plasma cells have been estimated to create 3-6 million disulfide bonds per minute, which leads to the production of a comparable amount of intracellular reactive oxygen species (ROS) [6]. ROS can act as a second messenger driving carcinogenesis, cancer progression and metastasis. The delicate balance between ROS generation and scavenging plays an important role in redox homeostasis which is intimately linked to proteostasis. However, excessively high level of ROS induces oxidative stress that promotes genomic instability, damage to membrane permeability and protein oxidative modification. UPR signaling is also regulated by redox-controlled reversible modifications. One example is thiol oxidation of ER molecular chaperons such as the binding immunoglobulin protein $(\mathrm{BiP} /$ Grp78) that facilitates the release of BiP from ER stress sensors and activates UPR [7]. Another example is cysteine sulfhydration of protein tyrosine phosphatase 1B (PTP1B) that promotes phosphorylation and activation of doublestranded RNA-activated protein kinase-like ER kinase (PERK), one of the major ER stress sensors [8]. In addition, ROS mediate cysteine sulfenylation of another ER stress sensor, inositol requiring enzyme $1 \alpha$ (IRE1 $\alpha)$, which activates nuclear factor-E2-related factor-2 (Nrf2) to generate an antioxidative response [9].

\section{The role of ER stress in multiple myeloma and drug resistance}

The ER is a specialized protein-folding factory where protein quality control mechanisms allow only properly folded and modified proteins to be transported out of the ER en route to other organelles or plasma membrane. Genetic profiling analysis revealed that approximately half of the MM patients harbor mutations affecting RNA processing, protein translation, proteostasis and UPR [10]. ER stress response is, therefore, regarded as the "Achilles heel" of MM [11, 12].

The resolution of ER stress through UPR can be achieved in multifaceted ways by translational attenuation, cell cycle arrest, expansion of the ER compartment, upregulation of chaperon-mediated protein folding and refolding, and removal of aberrant proteins through ER-associated degradation (ERAD) and/or autophagy. The UPR signaling pathway engages three ER stress sensors, IRE1 $\alpha$, PERK and activating transcription factor 6 (ATF6) (Fig. 1). Under unstressed conditions, transmembrane protein IRE1, PERK, and ATF6 form complex with BiP/Grp78, thereby preventing IRE1 or PERK homodimerization or nuclear translocation of ATF6. Accumulation of unfolded protein triggers BiP/Grp78 release from these ER stress sensors and activates UPR signaling. In this section, we focus on the recent progress in recognizing the practical ramification and therapeutic significance of UPR signaling pathways in MM.

\section{IRE1a}

Over the past decade, IRE1-mediated UPR, the most evolutionarily conserved signaling pathway in ER stress response, has been extensively studied for therapeutic potential in various types of cancers, including MM [13-16]. Activated IRE1 $\alpha$ catalyzes the removal of an intron from the X-box binding protein 1 (XBP1) mRNA, leading to a translational frame-shift and production of 


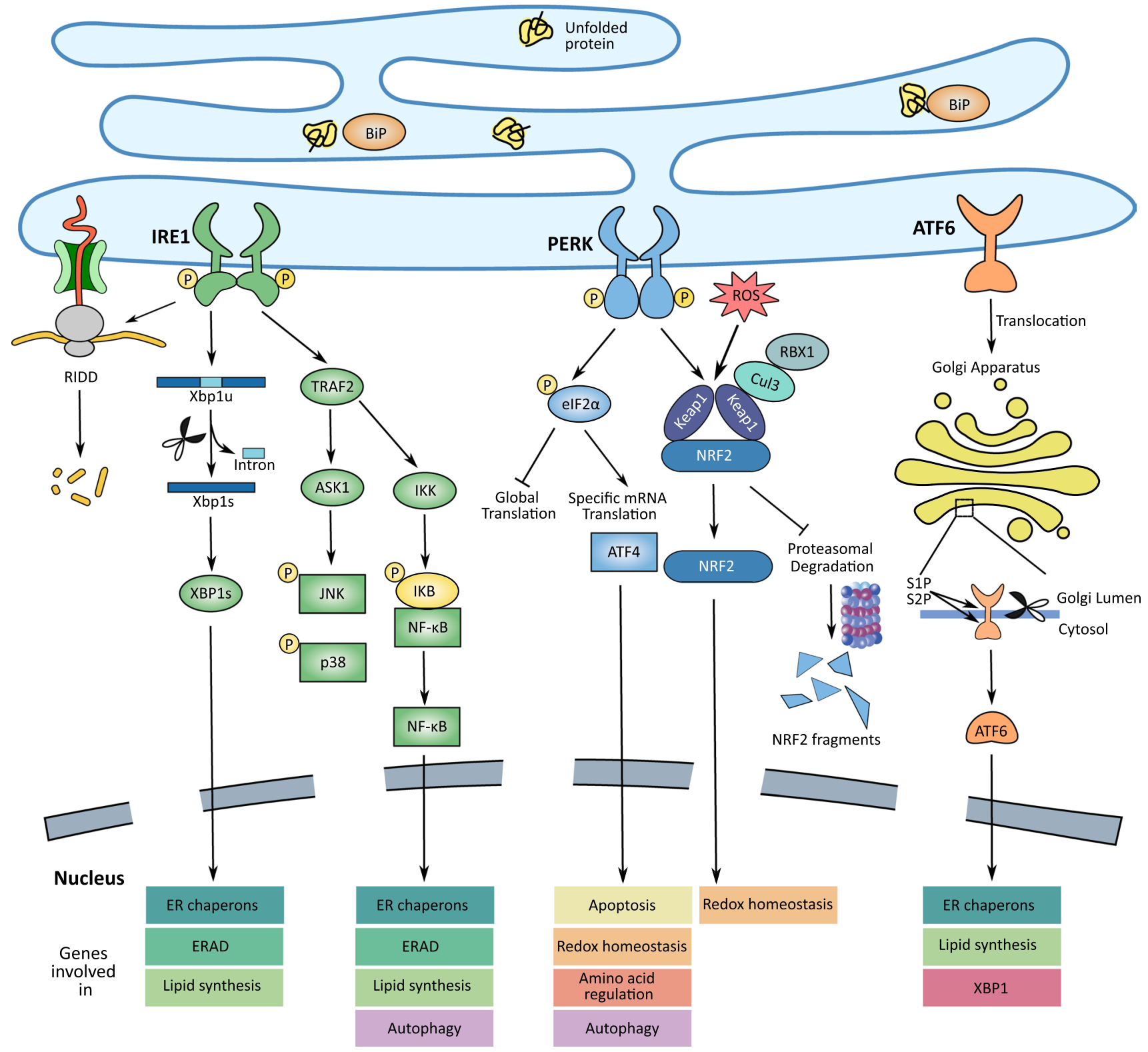

Fig. 1 Signaling pathways associated with the UPR. To maintain ER homeostasis, accumulation of unfolded proteins that are bound by BiP in the ER activates three ER stress sensors, including IRE1, PERK and ATF6. However, chronic or excessive unresolved ER stress redirects the UPR pathways to trigger apoptosis. Dimerization and auto-phosphorylation of IRE1 induces its kinase and endoribonuclease activities, leading to phosphorylation of JNK and inhibitor

an activated form of XBP1 [17] (Fig. 1). The spliced XBP1 induces transcriptional activation by modulating the expression of ER stress-responsive genes engaged in the ER membrane expansion, protein-folding machinery and ERAD, such as ER-resident chaperon p58IPK, BiP co-factor ERdj4, protein disulfide isomerase-P5 (PDI-P5) and ER degradation-enhancing alpha-mannosidase-like protein (EDEM) $[18,19]$. XBP1 is frequently upregulated of nuclear factor kappa B (IкB), unconventional splicing of XBP1 mRNA and RIDD. Similarly, dimerized PERK phosphorylates downstream targets eIF $2 \alpha$ and NRF2 in the absence of BiP. On dissociation of $\mathrm{BiP}$ in the ER lumen, ATF6 translocates to the Golgi apparatus, where it undergoes cleavage by site- 1 protease (S1P) and site-2 protease (S2P) to form the short-form ATF6 being redirected to the nucleus to mediate the expression of UPR downstream targets

in MM cells and serves as a pro-survival factor that controls immunoglobulin production and inhibits apoptosis through activation of nuclear factor- $\mathrm{KB}(\mathrm{NF}-\kappa \mathrm{B})$ and activator protein-1 (AP-1) signaling pathways. Gupta et al. showed that XBP1 splicing is enhanced by heat-shock protein $70 \mathrm{kDa}$ (HSP70) that protects cells from apoptosis under ER stress conditions. HSP70 also directly interacts with IRE $1 \alpha$ and upregulates its endonuclease 
activity [20]. XBP1 splicing has been implicated in drug resistance in MM, which is in part associated with HSPs. In conferring a protective effect against bortezomib, MM cells upregulate expression of HSPs such as HSP27, HSP70 and HSP90 concomitantly with an increase in XBP1 activity [21]. Inhibition of IRE1 $\alpha$ endonuclease domain or XBP1 splicing abrogates drug resistance in myeloma cells and increases sensitivity to proteasome inhibitors [15]. HSP70 and HSP90 inhibitors elicit similar effects with a negative impact on the stability of IRE1 $\alpha$ and XBP1 [22, 23].

$\mathrm{XBP} 1$ has been proposed as an independent prognostic factor in MM. It was reported that low XBP1 spliced/ unspliced ratio (XBP1s/XBP1u) is significantly correlated with improved overall survival and better clinical outcome in MM patients treated with immunomodulatory agent thalidomide [24]. In addition, higher level of total XBP1 mRNA expression predicts better clinical response in MM patients treated with bortezomib [25, 26]. Several groups have also shown that suppression of IRE1 $\alpha$-XBP1 signaling pathway contributes to acquired resistance to proteasome inhibitor (22-25). This is consistent with the observation that XBP1 knockdown weakens cytotoxicity of bortezomib, with XBP1s sensitizing cells to bortezomib [27]. Whole genome and exome sequencing of MM patients revealed two inactivating mutations in XBP1, P326R and L167I [10]. P326R, a missense mutation located within the transactivation domain of spliced XBP1 isoform has no effect on its transcription activity [28]. The other mutation, L167I is a splicing site mutation that impairs XBP1 signaling by reducing spliced XBP1 isoform while increasing the unspliced counterparts. Further research showed that XBP1-P326R and XBP1-L167I are unable to restore bortezomib sensitivity in XBP1 silenced-MM cells [27].

IRE1 $\alpha$ can switch from the adaptive mode to pro-apoptotic mode through JNK-mediated apoptotic pathways and IRE1-dependent decay of mRNA (RIDD) [29]. Although RIDD is believed to inhibit ER stress-induced cell death by alleviating protein translocational load [30], prolonged activation of RIDD potentiates apoptosis through degradation of ER protein chaperone mRNAs and antiapoptotic pre-microRNAs [31, 32]. Alternatively, IRE1 induces apoptosis via direct interaction with TNF receptor-associated factor 2 (TRAF2) and activates apoptosis signal-regulating kinase 1 (ASK1), followed by stimulation of C-Jun $\mathrm{N}$-terminal kinase (JNK) and p38 signaling pathways $[33,34]$. Oxidative stress also induces activation of ASK1 by dissociation of the ASK1-thioredoxin (TDX) complex in a ROS-dependent manner [35-37], indicating the presence of signaling connections between oxidative stress- and ER stress-induced apoptosis.

\section{PERK}

PERK is an ER-resident kinase that has two main UPRrelated substrates, eukaryotic initiation factor- $2 \alpha$ (eIF2 $\alpha)$ and Nrf2 (Fig. 1). In response to ER stress, activated PERK phosphorylates eIF2 $\alpha$ at Ser51 and blocks the formation of pre-initiation complex, inducing a temporary halt in the protein translation concomitant with selective mRNAs translation of genes such as activating transcription factor 4 (ATF4) and C/EBP-homologous protein (CHOP/GADD153). ATF4 induces translational upregulation of the ER chaperon genes and antioxidative stress-response genes to facilitate stress adaption [38]. The eIF2 $\alpha$ initiation factor induces ATF4independent activation of protein kinase B (AKT) by downregulating mammalian target of rapamycin complex 1 (mTORC1) that exerts negative feedback regulatory effects on the oncogenic phosphoinositide 3-kinase (PI3K)-AKT signaling pathway [39]. In addition, PERK regulates antioxidative response and detoxification through phosphorylation and activation of Nrf2 [40].

PERK is required for malignant transformation and survival of MM cells. Michallet et al. reported that inhibition of PERK-eIF2 $\alpha$ pathway in human MM cell lines exacerbates ER stress and promotes autophagic cell death due, at least in part, to the release of translational repression and amplification of the other two PERK-independent UPR pathways [41]. Interestingly, induction of autophagic pathway was found to suppress the mitochondrial apoptotic pathway in MM cells, indicating the role of PERK in metabolic regulation of plasma cell malignancy. This is corroborated by previous findings that PERK remains inactivated in association with ER chaperon p58IPK during normal plasma cell differentiation, whereas PERK expression is highly upregulated in myeloma cells $[42,43]$. The probability of developing drug resistance increases with elevated resistance to ER stress. PERK offers a growth advantage to carfilzomib-resistant MM cells by upregulating pro-survival autophagy to overcome excessive accumulation of misfolded proteins [44]. Activation of PERK also promotes transcription of drug efflux transporters, such as multidrug resistance-related protein 1 (MRP1) and p-glycoprotein (P-GP), driven by Nrf2 [45]. The phosphorylation of eIF2 $\alpha$ has been shown to mediate oxidative stress adaption in drug-resistant MM cells, rendered by enhanced cysteine transport and antioxidant glutathione (GSH) synthesis through activation of cystine/glutamate antiporter xCT (SLC7A11) [46, 47]. Therefore, targeting PERK-mediated regulatory axis is envisaged as a promising therapeutic strategy, but it is worth noting that inhibition of PERK may be accompanied by pancreatic toxicity.

However, PERK-eIF2 $\alpha$-ATF4 pathway has been shown to take part in a diametrically opposed function as a tumor suppressor. ATF4 may prompt cell death by inducing expression 
of genes encoding CHOP, growth arrest and DNA damageinducible protein (GADD34) and ATF3, thereby overwhelming the cytoprotection mechanisms by cell death mediators [48]. Moreover, ATF4 interacts with CHOP to implement transcriptional regulation that increases protein synthesis, leading to ATP depletion and ROS accumulation [49]. Bortezomib was shown to evoke mitochondrial apoptosis in MM cells by upregulation of $\mathrm{BH} 3$-only proteins and activation of BAX/BAK $[48,50]$, following upregulation of pro-apoptotic terminal UPR signaling components including PERK and its downstream effectors ATF4 and CHOP [51]. Sustained eIF2 $\alpha$ phosphorylation also exerts a death-promoting effect by activation of heme-regulated eIF2 $\alpha$ kinase (HRI) in dexamethasone-resistant primary myeloma cells [52]. While current research fails to provide a clear-cut answer with regard to the underlying mechanisms of PERK signaling in controlling the UPR commitment to survival or death, emerging data suggest that cell fate decision under ER stress may be determined by the intensity and duration of UPR signal in concert with innate immune response and surrounding bone marrow microenvironment of MM cells [53, 54].

\section{ATF6}

ATF6 is an ER transmembrane transcriptional activator of the ER stress-response element present in the promoters of various UPR-responsive genes, including the ER chaperon genes BiP, Grp94/Gp96, and P58 ${ }^{\mathrm{IPK}}$. The molecular mechanisms of ATF6 broadly overlap with the other ER stress sensors, although its role in MM remains largely unknown $[55,56]$. Both ATF6 and PERK culminate in the transcription of CHOP involved with programmed cell death induced by anti-myeloma drugs [57-59]. In contrast, ATF6 exerts cytoprotective effects against otherwise detrimental ER stress and oxidative stress in concert with IRE1 $\alpha[60,61]$. Specifically, ATF6 enhances XBP1 gene transcription, and splicing of XBP1 mRNA is mediated by IRE1 $\alpha$. Activation of both ATF6 and IRE1 $\alpha$ are necessary to achieve maximal induction of the UPR, as implicated in the process of antibody-secreting plasma cell differentiation and maturation. ATF6 may also have a critical role in maintaining MM cell viability. A profound reduction in cell survival was observed in MM cells after knockdown of ATF6 [41]. Recently, ATF6 has also been proposed as a predictor of bortezomib sensitivity in MM cells since drug resistance evolves to reduce cellular dependence on the UPR by downregulation of ATF6 and XBP1 expression [62].

\section{UPR and plasma cell development}

In addition to malignant transformation of plasma cells, normal plasma cell development also requires activation of UPR components, which is essential to accommodate increased demand on immunoglobin synthesis and counteract ER stress arising from B-cell differentiation process. Plasma cells play a central role in humoral antibody response and comprise at least two distinct populations: short-lived and long-lived plasma cells. Immature B cells migrate from the bone marrow to peripheral lymphoid organs, such as spleen and lymph nodes, where they achieve maturity and wait to be activated by foreign antigens. On encountering antigen, mature B cells rapidly differentiate into short-lived plasma cells (SLPC) that secrete predominantly IgM with low antigen-binding affinity in the peripheral lymphoid organs, while long-lived plasma cells (LLPC) residing primarily in bone marrow produce $\mathrm{IgG}$ with high stability and affinity, thus contributing to prolonged humoral immune response [63]. MM and LLPC share many common extrinsic and intrinsic survival mechanisms, underlining the importance of studying LLPC regulatory programs and the associated implications for MM disease progression and treatment. The bone marrow microenvironment provides critical extrinsic cues for survival and retention of MM and LLPC [64, 65]. For example, CD28 expression supports LLPC and MM survival and regulates immunoglobulin production via interaction with CD80/CD86-expressing stromal cells in the bone marrow niche $[66,67]$. In addition, MM and LLPC carry intrinsic programs, including increased basal level of autophagy, glycolysis and responsiveness to ER stress, which sustain cell viability and ensure efficiency and fidelity of protein secretion in response to nutrient availability [68].

The number and longevity of plasma cells are tightly controlled over the course of humoral immune response against pathogens. Majority of plasma cells succumb to apoptosis after a few days of exuberant secretion of antibody. However, key apoptotic caspases (caspase-3/9) are subject to inactivation favoring SLPC survival and sustained high level of immunoglobulin secretion under conditions of ER stress in an early phase [69]. ER stress progressively becomes overwhelmed due to decreased proteasomal capacity, resulting in protein overload and caspase-independent cell death despite activation of the UPR [70, 71]. Hence, the coordinated regulation of caspase activity and ER stress is important in the temporal control of plasma cell death to ensure proper early humoral immune response.

The process of B cell to plasma cell differentiation involves extensive chromatin remodeling and epigenetic modification that elicit upregulation of master transcription regulators and reprogramming factors such as IRF4, Blimp-1, and XBP1. IRF4 is induced in response to NF- $\kappa B$ activation and is required for plasma cell survival partly through inhibition of caspase activation [72]. IRF4 does not appear to regulate key anti-apoptotic B-cell lymphoma 2 (Bcl-2) family protein myeloid cell leukemia 1 (Mcl-1), but overexpression of Bcl-2 can rescue cell death induced by loss of IRF4 in plasma cells. IRF4 also functions as a 
dose-dependent regulator of germinal center (GC) B-cell formation and plasma cell differentiation [73]. IRF4 is present at low levels in follicular B cells and transient expression of IRF4 stimulates initiation of GC formation. Signaling through B-cell antigen receptor (BCR) and engagement of co-stimulatory receptor on $\mathrm{T}$ cells leads to increased level of IRF4, which upregulates Blimp-1 and subsequently antagonizes the expression of $\mathrm{Bcl6}$, a master regulator of the GC program. Hence, high levels of IRF4 induces B-cell exit from the GC reaction and reinforces plasma cell differentiation program. Notably, Blimp-1 shares overlapping functions with IRF4 in the regulation of UPR components and plasma cell identity. Specifically, Blimp-1 can induce the activation of ATF6 and its downstream effector XBP1, and also promote IRE1alpha-mediated XBP1 mRNA splicing [74, 75]. The downstream activation of XBP1 causes elevation of secretory pathway genes, ER expansion and lysosomal transport. In addition, Blimp-1 deficiency has been reported to attenuate immunoglobulin synthesis and secretion and decrease the activation of mTOR, without affecting the longterm survival of plasma cells [76].

UPR signaling branches are differentially activated during plasmacytic differentiation to optimize immunoglobulin production and secretion. Recent studies reveal that IRE1-XBP1 and ATF6 arms of the UPR are selectively activated upon lipopolysaccharide (LPS) stimulation of splenic B cells, whereas PERK-mediated signaling pathway is not induced after B-cell activation [77]. Reimold et al. reported that mice deficient in XBP1 have normal number of B cells but fail to generate antibody-secreting plasma cells [75], indicating an indispensable role of XBP1 in the terminal differentiation towards plasma cells. Indeed, XBP1 specifically regulates the synthesis of immunoglobulin $\mu$ heavy chains and ensures proper translocation of $\mu$ heavy chains to the ER [78]. Some studies have shown that expression of spliced XBP1 and cleavage of ATF $6 \alpha$ precede the induction of Immunoglobulin synthesis and reach a maximum when antibody production is significantly induced, while other studies found that initial ER expansion and IgM production may occur prior to activation of XBP1 $[55,79]$. ATF6 can also upregulate $\mathrm{XBP} 1$ expression through direct binding to its promoter, but it is believed that ATF6 alone is not sufficient to fully induce plasma cell differentiation as IRE1-mediated XBP1 mRNA splicing is required for activating XBP1 [80]. Furthermore, in contrast to the essential role of PERK in the normal development and secretory homeostasis of pancreatic $\beta$ cells, PERK is dispensable for plasma cell development. Previous studies found no significant differences between wildtype and $\mathrm{PERK}^{-/-} \mathrm{B}$ cells in terms of lifespan, viability as well as the ability to produce antibody in response to LPS [77, 81]. Although PERK is partially phosphorylated upon B-cell activation by LPS, it is not adequate to drive eIF $2 \alpha$ phosphorylation and activate other downstream targets, such as CHOP, GADD34. It remains elusive how PERK arm of the UPR is inactive during plasma cell differentiation. One plausible explanation involves suppression of the PERKmediated UPR by a negative regulator. Another possible mechanism is that, compared with IRE1 and ATF6, PERK may have a higher activation threshold in B cells. However, one study showed that ER stress inducers tunicamycin and thapsigargin exhibit comparable dose thresholds for the activation of XBP1 and CHOP [42].

\section{ER stress and autophagy}

Normal and malignant plasma cells are highly reliant on the ubiquitin-proteasome system (UPS) and autophagy, which constitute the major protein degradation machineries and play critical roles in eliminating unfolded or misfolded proteins to sustain biosynthetic capability. The UPS is responsible for clearance of short-lived proteins and soluble unfolded or misfolded proteins, while insoluble, aggregation-prone proteins and organelles can be sequestered into autophagosome and subsequently degraded by autophagosome-lysosome fusion [82]. When proteasomal degradation is inhibited, the basal autophagy level is rapidly upregulated in MM cells to compensate for impaired proteasomal function, which can be beneficial for cell survival and overcoming drug-induced cytotoxicity. The adaptive response to proteasome stress entails increased expression of autophagic receptor/adaptor sequestosome 1 (SQSTM1)/ p62 and altered interactome of SQSTM1/p62 that preferentially associate with ubiquitinated proteins [83, 84]. Recent studies have shown that SQSTM1/p62-mediated phase separation in autophagy regulates activation of the Nrf2-Keap1 signaling, thereby modulating redox homeostasis [85, 86]. Knockout of autophagy-related gene 5 (ATG5), an essential factor for autophagosome formation, gives rise to increased sensitivity to proteasome inhibitor MG-132, indicating the critical role of autophagy in regulating cellular response to proteasome inhibition [87]. Nevertheless, the clinical results of combined inhibition of proteasome and autophagic protein degradation have yielded contradictory results, which requires further delineation of the interconnection between UPS and autophagy [88, 89].

It is clear that both UPS and autophagy are involved in not only proteostasis but also amino acid homeostasis. In the absence of nutrient starvation, autophagy is maintained at low steady state levels, whereas UPS predominantly contributes to intracellular amino acid recycling. Autophagy can also be activated as an alternative mechanism for replenishment of the depleted amino acid pool in an attempt to alleviate amino acid scarcity induced by proteasome inhibition [90, 91]. The autophagy activation involves the PERK arm of the UPR and integrated stress response (ISR), which converge on eIF $2 \alpha$ phosphorylation and result in upregulation of 
transcription factor ATF4-mediated amino acid deprivation response. ER stress has been shown to elevate expression of ATG12 and mediate microtubule-associated protein light chain 3 (LC3) conversion during autophagosome formation via the PERK-eIF2 $\alpha$ signaling pathway [92]. Overexpression of ATG5 and ATG7 can increase autophagic flux and suppress ER stress [93]. In addition, in amino acid-starved cells, the accumulation of uncharged tRNAs activates eIF $2 \alpha$ kinase general control nonderepressible 2 (GCN2) that leads to induction of ISR signaling and alleviates mTORC1mediated suppression of autophagy [94]. GCN2 activation is required for cell survival upon inhibition of proteasome and ATPase p97 (VCP/Cdc48), an essential component of ubiquitination machinery [95].

\section{Modulation of oxidative stress in multiple myeloma}

In normal cells, redox homeostasis is maintained by elaborate regulation of ROS generation and antioxidant defense systems. Moderate increase in ROS has long been implicated in carcinogenesis and tumor progression, with functional effects on cellular proliferation, chromosomal instability and therapeutic resistance. However, excessive ROS production or impaired ROS scavenging capability at an unmanageable level can lead to oxidative stress and ultimate cellular death [96]. Endogenous ROS are mainly generated from mitochondria and peroxisomes. ER oxidative protein folding is another key source of ROS, particularly in secretory cells like antibody-producing plasma cells. The detrimental effects of ROS are counterbalanced by a comprehensive antioxidant defense systems comprising enzymatic antioxidants such as glutathione peroxidase (GPX), thioredoxin reductase (TrxR), catalase, peroxiredoxin (PRX) and superoxide dismutase (SOD), and non-enzymatic antioxidants such as GSH, thioredoxin (Trx), vitamin C, vitamin E, and metallothionein [97, 98].

Elevated level of ROS has been observed in numerous hematologic malignancies, and myeloma cells are no exception [99-101]. Studies have found that protein oxidation and lipid peroxidation are increased in MM patients when compared with healthy controls and MGUS patients, as measured by oxidative stress markers malondialdehyde (MDA) and advanced oxidation protein products (AOPPs) $[102,103]$. Nevertheless, the antioxidant activities of SOD, GPX, catalase, and vitamins were found to be significantly lower in MM patients than in healthy controls [104]. Indeed, the abundance of intracellular antioxidants varies across different types of cancer. In patients with chronic leukemia, antioxidant parameters are elevated [105]; however, decline in antioxidant defense was observed in acute myeloid leukemia (AML) [99], pancreatic [106] and prostate cancer [107].
It is hypothesized that depletion of antioxidants may be due to increased scavenging efforts to counteract pro-oxidants and lipid peroxidation in cancer cells. It is also plausible that active oxidative molecules oxidize and inactivate enzymatic antioxidants such as GPX and SOD [108].

Notably, proteasome inhibitors have been shown to evoke oxidative stress-induced cell death through elevation of ROS level, oxidation of mitochondrial cardiolipin and loss of mitochondrial membrane potential [109]. The level of antioxidant defense has been considered as a critical factor in determining drug susceptibility in MM as antioxidant capacity is markedly elevated in drug-resistant cells to reduce oxidative stress $[110,111]$.

\section{Oxidative protein folding and ROS}

Under ER stress conditions, the activity of ER chaperones and oxidoreductases increases as part of the effort to alleviate protein-folding burdens. The formation and isomerization of disulfide bonds, referred to as oxidative protein folding, are key steps in the post-translational modification of glycoprotein or secretory proteins [112]. This process involves electron transferring from reduced cysteine residues of the nascent proteins to protein disulfide isomerase (PDI) in an oxidized state. The resultant reduced PDI can be recycled by endoplasmic reticulum oxidoreductin-1 (ERO1) in a flavin adenine dinucleotide (FAD)-dependent reaction coupled with molecular oxygen reduction to hydrogen peroxide $\left(\mathrm{H}_{2} \mathrm{O}_{2}\right)$, thus completing a catalytic turnover [113]. Oxidative protein folding is, therefore, considered as a significant contributor to ROS generation in MM cells with high basal ER stress, suggesting MM hypersensitivity to oxidative stress $[114,115]$.

ERO1 and PDI have multifaceted roles in cancer progression associated with tumor growth, angiogenesis and metastasis [116, 117]. High level of ERO1 $\alpha$ expression was shown to be associated with poor overall survival rate in relapsed MM patients who received bortezomib or dexamethasone treatment [118]. ERO1 inhibitor EN-460 is sufficient to induce growth inhibition and apoptosis of MM cells, which is accompanied by exacerbation of ER stress due to upregulated ATF6- and eIF2 $\alpha$-mediated pathways. The ability of ERO1 $\alpha$ to promote cancer cell proliferation is mediated by glycosylation and activation of cell surface receptor integrin- $\beta 1$, specifically under hypoxic conditions [119]. Activation of ERO1 $\alpha$ activity may enhance vascular endothelial growth factor (VEGF)-mediated angiogenesis in low-oxygen environment such as bone marrow where MM cells reside. Studies have found that MM cells secret high levels of VEGF that enhance the expression of interleukin-6 (IL-6) and Mcl-1, leading to persistent cell survival and proliferation [120, 121]. A recent study reported that MM cells resistant to bortezomib or carfilzomib constitutively 
express high level of PDI, whereas in drug-naïve parental cell line, PDI expression is strongly induced upon drug treatment [122]. Moreover, ER-resident peroxiredoxins IV (PRDX4) has a crucial role in the acceleration of oxidative protein folding by oxidation of PDI while catalyzing peroxide detoxification. PRDX4 is linked to immunoglobulin secretion, which is beneficial for B-cell differentiation and plasma cell malignant transformation [123].

Futile cycles of disulfide bond formation/isomerization and reduction driven by protein misfolding can lead to depletion of GSH, the most abundant antioxidant agent in the cells, thus further increasing ROS accumulation. GSH serves as a thiol/disulfide redox buffer that directly reduces improper disulfide pairings in proteins, allowing for another attempt of protein folding into the correct configuration [124, 125]. In addition, GSH reduces PDI and its homolog ERp57/Grp58, antagonizing oxidative stress by regulating disulfide bond formation rate [126]. The excessive consumption of GSH produces a copious amount of glutathione disulfide (GSSG) that exceeds the GSH recovery capacity governed by the glutathione reductase (GSH-Rd) and $\gamma$-glutamylcystein synthetase (GCS), ultimately leading to dysregulation of redox homeostasis. Of note, increased activities of GSH and GCS were observed in drug-resistant myeloma cell lines [127]. Further mechanistic study revealed that abrogation of bortezomib-induced apoptosis is partially mediated through inhibition of transcription factor Nrf2associated downstream signaling that increases the GSH pool through upregulation of the $\mathrm{xCT}$ subunit of the Xccystine-glutamate antiporter [128]. A recent study revealed that FAM46C, one of the most recurrently mutated genes in $\mathrm{MM}$, promotes ER expansion and augments immunoglobulin secretion, thus leading to a remarkable increase in oxidative stress that goes beyond the cellular capacity to maintain sustained proteostasis [129]. These findings are in line with previous research indicating that loss of oncosuppressive FAM46C confers a survival advantage to MM cells and poor prognosis in MM patients [130, 131]. Evasion of oxidative stress renders drug tolerance through several possible mechanisms including regulation of drug efflux by glutathione conjugation to xenobiotic compounds [132], suppression of p38 and JNK mitogen-activated protein kinase (MAPK) signaling pathways $[133,134]$ and removal of free radicals and lipid peroxides [135]. A recent genotyping study revealed the association between GST genetic polymorphism and MM susceptibility [136].

\section{NOX and ROS}

NOX/dual oxidase (DUOX) is a family of transmembrane proteins that catalyze electron transfer from NADPH to molecular oxygen and generate ROS [137]. Mechanisms of NOX-dependent ROS generation have been previously reviewed [138, 139]. Seven isoforms of the NOX/DUOX enzyme family, which include NOX 1-5, DUOX1, and DUOX2, have been identified [140]. These isoforms exhibit differences in tissue distribution, intracellular localization, regulatory network and types of ROS generated. A large number of studies have elucidated the importance of NOX2dependent ROS production in B-cell activation and differentiation [141-143]. NOX2 is the most abundant NOX/DUOX isoform in B lymphocytes, whereas other isoforms are expressed at very low or undetectable levels. Intriguingly, B cells from mice deficient in NOX2 or its catalytic subunit p47phox have severely impaired ROS-generating capability without alterations in the BCR signaling and antibody response following BCR stimulation [144, 145]. However, the finding that universal ROS scavenger $\mathrm{N}$-acetylcysteine (NAC) inhibits BCR signaling indicates that NOX2 is involved in the early stage of BCR-dependent ROS production, whereas later stages of B-cell activation may require other sources of ROS, presumably mitochondria.

Increasing evidence points to the integral roles of NOX2 and NOX4 in the ER stress response, although their functional and clinical relevance in MM have not been extensively studied [146, 147]. Toll-like receptor (TLR)-dependent splicing of XBP1 mRNA is regulated by TRAF6 and NOX2. In MM, TLR4 activation contributes to cell proliferation and downregulation of CHOP and ATF4. NOX2derived ROS are associated with the pro-apoptotic CHOPCalcium/calmodulin-dependent protein kinase II (CaMKII) pathway, in which NOX2 promotes feed-forward amplification of CHOP through activation of double-stranded RNAdependent protein kinase (PKR) and phosphorylation of its substrate eIF2 $\alpha$. On the other hand, NOX4-derived ROS inactivate protein tyrosine phosphatase 1B (PTP1B) that induces IRE $1 \alpha$ - and eIF $2 \alpha$-mediated signaling pathways in response to ER stress [148, 149]. PTP1B oxidation has also been shown to elicit cellular senescence downstream of RAS [150], which may be related to myeloma pathogenesis since RAS is the single most frequently mutated oncogene in MM. Several studies have alluded to the tumor suppressive role of PTP1B in hematologic disorders, whereas its oncogenic role has been validated predominantly in solid tumor studies [151]. Dubé et al. reported that PTP1B deficiency in mice results in increased B cells in the bone marrow and lymph nodes, thus increasing the susceptibility to B lymphoma [152]. Le Sommer et al. reported that myeloidspecific PTP1B deficiency promotes cell survival and AML development in mice [153].

\section{Mitochondrial ROS}

Mitochondria are important sources of ROS, metabolic byproducts resulted from electron leakage in the electron transport chain. Complex III is the major site of superoxide 
${ }^{-} \mathrm{O}_{2}{ }^{-}$production under normal conditions while higher level of mitochondrial ROS is generated from complex I under many pathological conditions [154]. Mitochondrial ROS have garnered attention for playing a pivotal role in tumorigenesis. Complex III-derived ROS are required for hypoxiainducible factor (HIF) stabilization during hypoxia, which increases glucose metabolism in glycolysis by upregulating the expression of glycolytic enzymes and glucose transporters, and shunts pyruvates away from oxidative metabolism by increasing pyruvate dehydrogenase kinase 1 (PDK1) [155]. Mitochondrial ROS have also been shown to oxidize and inactivate phosphatase and tensin homolog (PTEN), PTP1B and protein phosphatase 2A (PP2A), leading to activation of PI3K-AKT signaling pathway.

Mitochondria, as the central regulatory hub of $\mathrm{Ca}^{2+}$ homeostasis, are involved in absorption and buffering of cytosolic $\mathrm{Ca}^{2+}$, which is required for metabolic adaption to increased energy demand, and maintaining antioxidative capacity of reduced NADH and NADPH [156]. Unmitigated oxidative stress or ER stress may induce $\mathrm{Ca}^{2+}$ leakage from the ER and subsequent $\mathrm{Ca}^{2+}$ accumulation in the mitochondria, resulting in release of cytochrome $\mathrm{c}$ and second mitochondria-derived activator of caspase (smac) and ultimately activation of apoptotic signaling cascades [157]. Increased mitochondrial $\mathrm{Ca}^{2+}$ in turn collapses mitochondrial membrane potential $\left(\Delta \Psi_{\mathrm{m}}\right)$ and enhances ROS production through multiple mechanisms including increase in ubisemiquinone radicals due to blockade of electron transport at complex III, increase in $\mathrm{O}_{2}$ consumption by activation of Krebs cycle dehydrogenases, disruption of the electron transport chain by increased NO production and depletion of GSH pool [158]. This ROS-induced ROS-release process constitutes a positive feedback loop amplifying the cell death signals.

Recent studies, albeit limited, have shed light on the mitochondrial dependency for the development of MM $[159,160]$. Intercellular transport of mitochondria from bone marrow stromal cells to MM cells was reported to render survival and proliferative advantage to MM cells via a CD38-dependent mechanism through elevation of oxidative phosphorylation and glycolysis [161]. It was believed that metabolic activities of MM cells rely primarily on glycolysis in the hypoxic bone marrow niche, while recent studies provide compelling evidence that the oxidative phosphorylation pathway is gradually upregulated in the process of MM development as well as in bortezomib-resistant MM cells. Single cell RNA sequencing analysis of CD138 + cells from $15 \mathrm{MM}$ patients at different disease stages revealed that the expression of genes related to oxidative phosphorylation is lowest among MGUS patients and highest among patients with $t(4 ; 14)$ translocations [162]. Another interesting study showed that missense mutations in mitochondrial genes encoding components of complex I (MT-ND2, MT-ND4, and MT-ND5) and cytochrome c oxidase (MT-CO3) occur frequently in patients with relapsed $\mathrm{MM}$, indicating the alterations of bioenergetics and metabolism in MM progression [163]. Consistent with these findings, previous studies found that mitochondrial dysfunction may confer drug resistance in MM cells characterized by $\Delta \Psi_{\mathrm{m}}$ hyperpolarization, high basal mitochondrial $\mathrm{Ca}^{2+}$ level and oxygen consumption rate [164]. Hence, resistant MM cells may be more susceptible to drug-induced mitochondrial oxidative stress than their drug-naïve counterparts.

\section{Nrf2 as a nodal regulator of ER stress and oxidative stress}

Oxidative insults can potentiate ER stress responses to neutralize ROS accumulation originated from excessive oxidative protein folding, mitochondrial respiration and detoxification. ROS direct sulfenylation of cysteine residues within the IRE1 kinase activation loop, inhibiting the IRE1-mediated UPR signaling and activating Nrf2 antioxidant stress responses [9]. The PERK-eIF2 $\alpha$-ATF4 pathway constitutes the integrated stress response that undergoes redox regulation, the activation of which is provoked by hypoxic conditions that prevent cells from ATP depletion through attenuation of global protein synthesis. A functional link between PERK and oxidative stress-induced PI3K-AKT pathway has been delineated $[39,165]$. The eIF $2 \alpha$ kinases PERK and general control non-derepressible-2 (GCN2) are required for AKT phosphorylation and activation, which are mediated by a negative feedback loop induced by mTORC leading to reduced eIF $2 \alpha$ phosphorylation. Recently, ATF6 has been found to induce expression of antioxidant genes such as catalase, peroxiredoxin $5(\operatorname{Prdx} 5)$ and valosin-containing protein-interacting membrane protein through increased gene transcription in response to oxidative stress [166].

Nrf2 is one of the key convergent points linking ER stress and oxidative stress. It is normally sequestered by microtubule-associated protein kelch-like ECH-associated protein 1 (Keap1) in the cytosol and targeted for degradation by the ubiquitination-proteasome machinery. Nuclear translocation of Nrf2 requires its dissociation from the Keap1Cul3-RBX1 complex and inhibition of degradation by the ubiquitination-proteasome pathway, which typically occurs in response to oxidative stress, ER stress or xenobiotic exposure $[167,168]$. Activated transcription factor Nrf2 regulates the intracellular redox homeostasis by inducing the expression of a repertoire of antioxidant and detoxifying genes, including GST [169], SOD [170], heme oxygenase-1 (HO1) $[40]$ and $\mathrm{NAD}(\mathrm{P}) \mathrm{H}$ :quinone oxidoreductase-1 (NQO1) [171], while reducing NOX expression [172]. The cysteine residues of Nrf2 are critical for sensing oxidant inducers and repressing Keap1-dependent degradation of Nrf2 [173]. 
Nrf2-Keap1 complex is localized at the outer mitochondrial membrane through interaction with phosphoglycerate mutase 5 (PGAM5) containing a mitochondrial-localization sequence [174]. This localization allows Nrf2 to sense mitochondrial ROS in vicinity and regulate stress defense. Various regulatory mechanisms of Nrf2 signaling have been described. These include cysteine oxidative modification of Keap1 that induces conformational change in Keap1, thus leading to Nrf2 release from Keap1 [175]. ROS can directly activate Nrf2 and influence protein turnover of Nrf2 through rapid induction of de novo synthesis of Nrf2. Besides oxidative modification, other post-translational modifications that regulate Nrf2 signaling include phosphorylation/dephosphorylation and acetylation/deacetylation [176, 177].

Besides its regulatory role in redox balance, $\mathrm{Nrf} 2$ has an overlapping but distinct role in ER stress responses. Nrf2 functions as a direct substrate of PERK that transduces UPR signal to the nucleus. PERK-Nrf2 pathway negatively regulates the CHOP-mediated apoptosis by inhibition of ATF4 binding to CHOP promoter [178]. PERK knockout was shown to interfere with protein synthesis that results in endogenous peroxide accumulation and increased level of pro-apoptotic ER stress marker CHOP [46, 179]. The resulting translational dysregulation could also be linked to impaired formation of stress granules (SG), which are non-membranous cytoplasmic foci that sequester nontranslating mRNAs with stalled translation initiation to promote cellular survival under stress conditions. The assembly of $\mathrm{SG}$ is mediated by redox balance between $\mathrm{NAD}(\mathrm{P}) \mathrm{H}$ and $\mathrm{GSH}$, and has been implicated to suppress arsenite-induced ROS generation by controlling and coordinating the activities of two SG components, GTPase-activating protein SH3 domain binding protein 1 (G3BP1) and ubiquitin-specific protease 10 (USP10) [180, 181]. Under most circumstances, SG formation is dependent on the phosphorylation of eIF2 $\alpha$ by PERK and other kinases [182]. Apart from direct phosphorylation of Nrf2 by PERK, Nrf2 can be activated through dimerization with ATF4, a canonical downstream factor of PERK [183]. Notably, Glover-Cutter et al. reported that $\mathrm{SKN}-1$, the C. elegans functional ortholog of Nrf2, is regulated by ER sentinel proteins IRE1 and PERK, and controls transcriptional responses to ER stress [184]. In keeping with this finding, IRE1 was shown to trigger p38 MAPK-mediated antioxidant response driven by Nrf2 [9]. JNK is also capable of phosphorylating and activating Nrf2, indicating the potential involvement of IRE1-TRAF2-JNK pathway in the regulation of Nrf2. Moreover, Nrf2 is involved in the alleviation of proteotoxic stress by escalating pro-survival autophagy through phosphorylation of autophagy receptor SQSTM1/p62 when ubiquitin-proteasome pathway activity is undermined. SQSTM1/p62 is a target gene of Nrf2, which forms a positive feedback loop contributing to the acquisition of resistance to proteasome inhibitors in MM cells [44,
185]. Collectively, these findings imply that Nrf2 plays a pivotal role in orchestrating redox homeostasis under the control of UPR signaling.

A recent study found constitutive expression of Nrf2 in MM cell lines and about $50 \%$ of the primary MM cells tested [186]. Interestingly, Wruck et al. reported that Nrf2 is a potent transcriptional activator of IL- 6 that binds to the antioxidant response element sequence in the promoter region of IL-6 gene [187]. IL-6 is a growth and survival factor in MM that promotes osteoclastogenesis and modifies bone marrow microenvironment favorable to disease progression. In addition, genetic silencing of $\mathrm{Nrf} 2$ in proteasome inhibitortreated MM cells exacerbates ER stress and oxidative stress through dysregulation of GSH generation and CHOP expression, thus resulting in increased cell death. This is consistent with other reports showing that genetic and pharmacologic inhibition of Nrf2 re-sensitizes drug-resistant myeloma cells to carfilzomib and bortezomib, supporting the notion that malignant plasma cells may hijack the cytoprotective Nrf2mediated pathways to fuel MM progression and therapeutic resistance $[188,189]$.

\section{UPR and HIF underlying hypoxic adaption in multiple myeloma}

It is well established that hypoxia, or insufficient oxygen supply, is a characteristic feature of tumor microenvironment driving cancer advancement and therapeutic resistance, which also holds true for MM residing in a hypoxic bone marrow niche [190]. Bone marrow is a special type of tissue with an unusually low-oxygen tension $\left(\mathrm{pO}_{2}\right)$ and a heterogeneous distribution of $\mathrm{pO}_{2}$ ranging from 1-6\% ( 7-43 $\mathrm{mm}$ $\mathrm{Hg}$ ) which provides a conducive condition for hematopoiesis [191]. Emerging evidence suggests that hypoxia encourages MM cell dedifferentiation and quiescence by reducing plasma cell-specific transcription factors (BLIMP-1, IRF4, XBP1), increasing B-cell gene expression signatures (PAX5, CD19, CD20 and CD45) and stem-cell markers (OCT4, NANOG, SOX2), as well as inducing reversible cell cycle arrest [192, 193]. Given the frequent occurrence of anemia in MM, it is plausible that alterations in the bone marrow microenvironment in MM may redirect the process of hematopoiesis to stem-cell maintenance while limiting the commitment of hematopoietic progenitors to differentiation and maturation. Furthermore, hypoxia can lead to myeloma cell migration to secondary sites in the bone marrow via adoption of the properties of epithelial-mesenchymal transition (EMT) [194].

Tumor cells that survive under hypoxic conditions elicit adaptive responses that entail a decrease in oxygen consumption and energy expenditure, and transcriptional reprogramming that maintains hypoxic tolerance, which mostly 
involve UPR and HIF pathways [195]. Differential activation of these hypoxic responses depends primarily on the magnitude and duration of hypoxia. PERK-eIF2 $\alpha$ pathway activation under moderate hypoxia $(0.5-1 \%)$ requires longer duration of exposure than in more severe hypoxia $(<0.05 \%$ $\mathrm{O}_{2}$ ) [196], whereas HIF- $1 \alpha$ protein has lower activation threshold as compared to UPR and can be activated under mild and moderate hypoxia $(<2 \%)$ [197]. The functional importance of PERK as a cytoprotective mediator against hypoxia-induced cell death has been supported by previous studies showing that abrogation of PERK-eIF2 $\alpha$-ATF4 signaling in tumor cells (e.g., PERK $^{-1-}$ mice cells expressing dominant-negative PERK allele or inactive eIF2 $\alpha$ mutant) results in a decrease in cell viability and clonogenic capability under hypoxia [198-200]. PERK-dependent eIF2 $\alpha$ phosphorylation has been found to be indispensable for the survival of a subpopulation of hypoxic tumor cells highly resistant to chemotherapy attributable to GSH synthesis induction and ROS defense [201]. Whether this is a universal mechanism applicable to MM requires further investigation. It was also reported that HIF- $1 \alpha$ confers survival advantage to tumor cells under hypoxic conditions, whereas compromised HIF-1 signaling neither significantly sensitizes tumor cells to cycling hypoxic stress nor affects the emergence of radiation-resistant cells. This indicates that PERK and HIF may support hypoxic cell survival through different but related mechanisms. The interaction between UPR and hypoxia response pathways enhances transcriptional activation of HIF-1 and its target gene expression [202]. However, proteasome inhibitor-induced ER stress can suppress HIF- $1 \alpha$ activity under moderate hypoxia by inhibiting HIF- $1 \alpha$ mRNA translation via PERK pathway, the activation of which leads to the redistribution of RNA-binding protein Y-box binding protein 1 (YB-1) to stress granules that prevents it from associating with HIF-1 $\alpha$ mRNA [203, 204].

IRE1-mediated XBP1 mRNA splicing serves as another major determinant of cellular response to hypoxia. Hypoxia induces activation of the IRE1 arm of the UPR and upregulation of XBP spliced protein [205]. XBP1 in turn regulates transcriptional response to hypoxic stress via colocalization with the HIF- $1 \alpha$ at the common regulatory element as confirmed by CHIP-seq and motif analysis [206]. XBP1 deficiency impedes tumor growth by sensitizing tumor cells to hypoxic cell death with negligible impact on the expression and secretion of angiogenic growth factors, suggesting that XBP1 may directly contribute to tumor growth under hypoxic conditions that circumvents the necessity for angiogenesis [207]. Mimura et al. reported that IRE1 $\alpha$ inhibitor MKC-3946 prevents XBP1 splicing and inhibits the growth of $\mathrm{MM}$ cells under hypoxic condition in vitro and in vivo using a murine xenograft model SCID-hu with a transplanted human bone marrow [15]. Unlike the pro-survival effects of PERK and IRE1 in the adaptation to hypoxia,
ATF6 and ATF4 have been mainly implicated in the regulation of ER stress-induced apoptosis during hypoxia by increasing CHOP expression under the control of HIF- $1 \alpha$ [208, 209].

Hypoxia induces ROS production despite insufficient oxygen supply, while ROS stabilize HIF- $\alpha$ by inactivating its negative regulator prolyl hydroxylase domain protein. The accumulation of HIF- $\alpha$ and subsequent binding to the dimerization partner HIF- $\beta$ is a crucial step toward activation of the hypoxic adaptive response, which controls the expression of a broad spectrum of genes implicated in multiple aspects of cancer progression, such as cell survival, proliferation, erythropoiesis, angiogenesis, glycolytic metabolism, cell cycle regulation and redox homeostasis $[210,211]$. Other studies have led to a new hypothesis, wherein ROS stimulate ERK and PI3K-AKT pathways and subsequently increase HIF- $1 \alpha$ at the levels of transcription and translation through intermediate regulators such as mTOR, Ras-related C3 botulinum toxin substrate 1 (Rac1) and histone deacetylase (HDAC) [212]. High constitutive expression of HIF-1 $\alpha$ and HIF-2 $\alpha$, which are positively correlated with bone marrow angiogenesis by upregulation of VEGF and stromal cellderived factor 1 (SDF1), were observed in several MM cell lines and biopsy specimens from MM patients [213-216]. Raninga et al. reported that hypoxia induces NF- $\mathrm{KB}$ signaling by elevating TrxR1 protein levels in bortezomib-resistant MM cells, whereas knockdown of TrxR1 and redox protein thioredoxin 1 (Trx1) reverses drug resistance [217, 218]. HIF-1 $\alpha$ overexpression can lend support to drug resistance in MM cells mediated by activation of NF- $\mathrm{KB}$, ERK and PI3K-AKT [219, 220]. These signaling pathways are activated during both hypoxic and ER stress response, which supports the notion of signaling crosstalk between hypoxia and UPR in fine-tuning tumor cell adaptation and apoptotic pathways in MM [221].

\section{Mitochondria-associated ER membrane facilitating crosstalk between ER and mitochondria}

Mitochondria-associated ER membrane (MAM) is a specialized subcellular entity formed by physical interaction between the ER and mitochondria that is closely linked to oxidative and ER stress responses (Fig. 2). MAMs are enriched with redox-sensitive calcium handling proteins, such as $\mathrm{IP}_{3} \mathrm{R}$, sarco/ER $\mathrm{Ca}^{2+}$-ATPase (SERCA) pumps and modulators of mitochondrial $\mathrm{Ca}^{2+}$ uniporter (MCU), whose activities are controlled by regulatory proteins mediating $\mathrm{Ca}^{2+}$ flux dependent on local ROS concentrations [222-224]. A recent study revealed that one of the ER stress sensors, PERK, is an essential member of MAMs involved in $\mathrm{Ca}^{2+}$ signal transmission and ROS signal propagation from the ER 


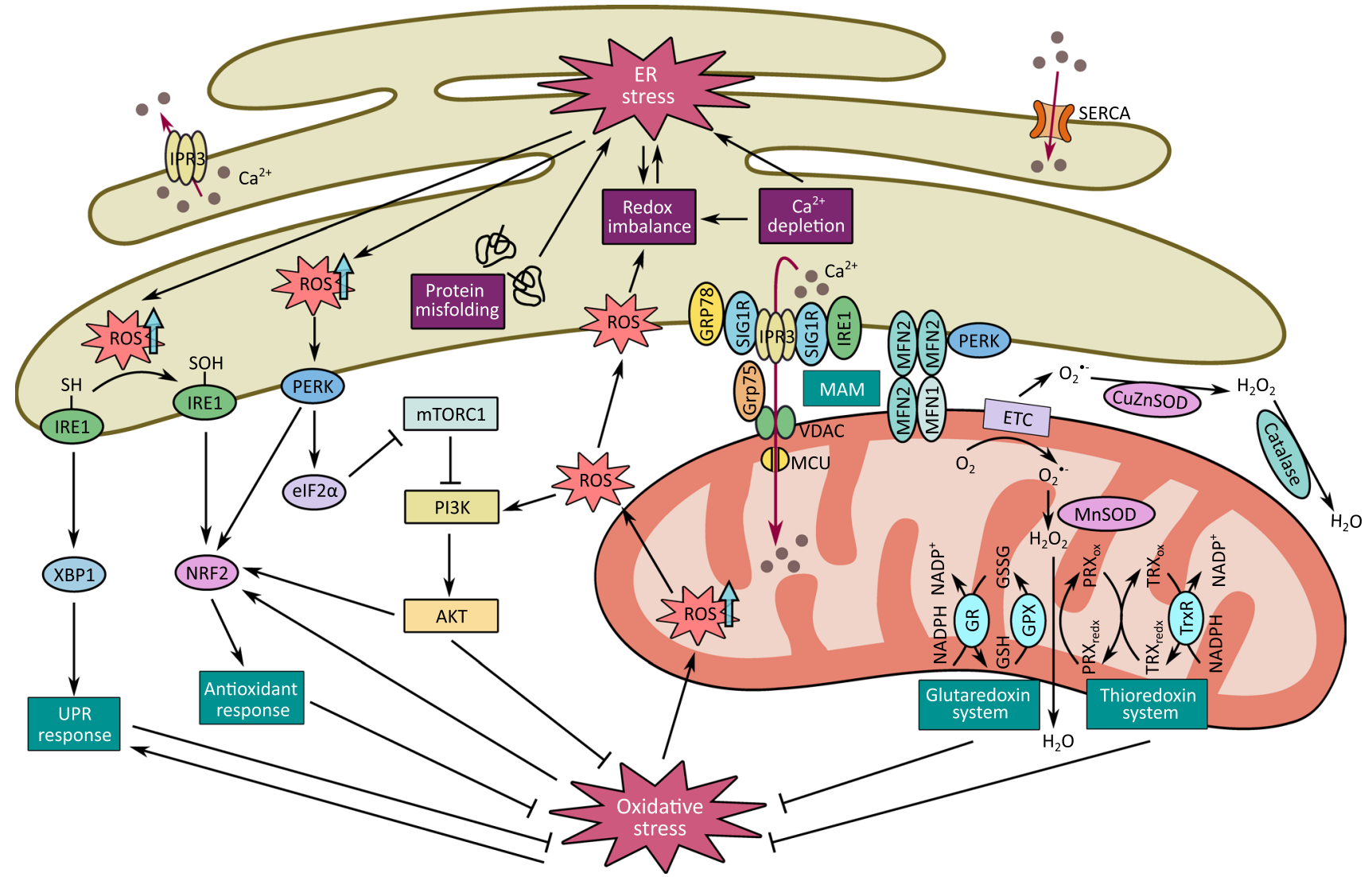

Fig. 2 Crosstalk between UPR and redox signaling. ER stress occurs when $\mathrm{ER} \mathrm{Ca}^{2+}$ is exhausted or ROS are overproduced due to cumulative load of protein misfolding and high energy demand. This in turn leads to redox regulation of UPR pathways. Cysteine oxidation of IRE1 drives a pathway switch to activation of Nrf2 and antioxidant responses. Redox-sensitive PERK also activates PI3K-AKT pathway to mitigate oxidative stress, while AKT may facilitate Nrf2 activation. IRE1 and PERK are key components of MAM for maintaining ERmitochondria juxtaposition and ROS-dependent mitochondria apoptosis

peroxisome and ER through physical interaction between the peroxisomal transmembrane protein ATP-binding cassette sub-family D member 3 (ABCD3) and ER-resident ATF6 $\alpha$, thus inhibiting ATF6-mediated UPR signaling [231].

The functional roles of MAMs have been investigated in several types of solid cancer, such as breast, lung and prostate cancer, yet the activity of MAMs in hematologic malignancies remains to be elucidated [232]. Signaling crosstalk between the ER and mitochondria is suspected to play a role in cancer cell survival and stress tolerance in some hematologic disorders such as MM, AML and chronic lymphocytic leukemia, that display elevated levels of Bcl-2 family proteins involved in ER-mitochondrial $\mathrm{Ca}^{2+}$ dynamics [233]. Bcl-2 proteins have been observed at the MAMs. The BH3 domain of Bcl-2 protein interacts with pro-apoptotic proteins (e.g., Bim) and imposes inhibitory effect on apoptosis, whereas its $\mathrm{BH} 4$ domain interacts with $\mathrm{IP}_{3} \mathrm{R}$ isoforms, thus prevents $\mathrm{Ca}^{2+}$ flux into mitochondria and promotes cancer cell survival [234]. Recently, a decoy peptide Bcl-2-IP ${ }_{3} \mathrm{R}$ disrupter-2 (BIRD-2) targeted to the $\mathrm{BH} 4$ domain of $\mathrm{Bcl}-2$ has been developed for cancer 
treatment. In vitro and in vivo studies have demonstrated that BIRD-2 propels $\mathrm{IP}_{3} \mathrm{R}$-mediated $\mathrm{Ca}^{2+}$ signaling and causes pronounced apoptosis in Bcl-2 positive cancer models, including MM, follicular lymphoma and chronic lymphocytic leukemia [235]. Therefore, we may speculate that MAM and its associated membrane protein interaction may be a critical contributing factor in MM progression. Further investigations of this regulatory mechanism in the context of hematologic malignancies are warranted.

\section{Anti-myeloma therapeutic options targeting ER and oxidative stress}

Over the past 15 years, substantial work has been dedicated to elucidating the biological and molecular mechanisms underlying MM pathogenesis, which have paved the way for the evolution of targeted therapeutic approaches. Several of these medications, including proteasome inhibitors, such as bortezomib, carfilzomib and ixazomib, HDAC inhibitor panobinostat and immunotherapies, such as immunomodulatory drugs (IMiDs) thalidomide and lenalidomide, monoclonal antibodies elotuzumab, daratumumab and the newly approved isatuximab, have been incorporated into treatment regimens as either mono- or combinatorial therapy [236]. The cytotoxicity of proteasome inhibitor, one of the first-line therapies for transplant-ineligible MM patients, is primarily attributable to amino acid deprivation, ERAD blockade and activation of PERK- and ATF6-mediated UPR pathways, which result in lethal ER stress and cytosolic oxidative damage due to mitochondrial dysregulation [51, 87, 237, 238]. It was considered that proteotoxic burden of undegraded proteasome substrates is underlying cause of proteasome inhibitor-induced cell death. However, there is increasing evidence that proteasome inhibition leads to lethal amino acid depletion, which can be rescued by amino acid supplementation while leaving the level of proteasome substrates unaffected [239]. Despite its demonstrated clinical success, many patients acquire tolerance to proteasome inhibitor and even develop cross-resistance to different proteasome inhibitors as the treatment proceeds, while some display intrinsic resistance due to relatively low proteasome activity [240]. The diverse sensitivity of MM cells to proteasome inhibitors can be explained by a prevailing model of proteasomal "load versus capacity", which suggests that proteasome inhibitorsensitive cells have a higher level of degradative workload and lower proteasome copy number and activity compared to their resistant counterparts [241]. In this regard, the short-lived rapidly degraded polypeptides (RDP), which are degraded within minutes after synthesis and may compete with endogenous ERAD substrates for proteasome-mediated degradation, accounts for a substantial fraction of newly synthesized proteins and imposes a significant workload on the ubiquitin-proteasome system [242, 243]. In MM cell lines and primary MM cells, a positive correlation has been observed between the responsiveness to proteasome inhibitor and the amount of polyubiquitinated proteins. The accumulation of polyubiquitinated proteins is accompanied by reduced availability of free ubiquitin under proteasomal stress in drug-sensitive MM cells. Taken together, the delicate balance between proteasomal capacity and functional workload could be exploited for therapeutic intervention against proteasome inhibitor resistance. This notion is supported by earlier findings indicating the synergistic cytotoxicity of ER stress-inducing drugs and proteasome inhibitors [244, 245].

The adaptive resistance arises through various mechanisms, including mutations in the $\beta 5$ subunit (PSMB5) of $20 \mathrm{~S}$ proteasome [246], activation of NF- $\mathrm{KB}$ [247] and insulin-like growth factor-1 (IGF-1) signaling pathways [248], reduced dependence on UPR [27], upregulation of antioxidant response [249] and autophagic activity [250] (Fig. 3). The reader is referred to recent reviews on detailed resistance mechanisms of proteasome inhibitor [251, 252]. Hence, perturbation in redox homeostasis and mitochondrial energy metabolism may sensitize resistant cells to apoptosis and improve the efficacy of current treatment when used in combination with novel targeted agents. Therapeutic interventions targeting the UPR, particularly IRE $1 \alpha / \mathrm{XBP} 1$ and PERK, are in preclinical stages of development, as illustrated in Table 1. Notably, pharmacological inhibition of PERK may lead to pancreatic injury, a common side effect observed in animal models including mice, rats and dogs, and is ascribed to the other PERK function independent of ER stress response [253, 254]. Similarly, systematic disruption of IRE1 $\alpha$ function may be accompanied by pancreatic exocrine dysfunction and/or hyperglycemia, which suggests that caution should be exercised when translating the experimental results of UPR targeting drugs into human clinical trials [255].

Encouraging preclinical results have been obtained when treating MM cells with ROS-inducing agents and other drugs that induce mitochondrial toxicity (Table 1). The cytotoxicity mechanisms of ROS-inducing agents involve dysregulation of different facets of antioxidant defense including the thioredoxin system, glutaredoxin system, SOD and catalase. Of these compounds, auranofin, arsenic trioxide $\left(\mathrm{As}_{2} \mathrm{O}_{3}\right)$ and disulfiram (DSF), which are FDA-approved therapeutic options for other malignancies, are undergoing further research to be repurposed for treatment of MM. Auranofin and PX-12, a thioredoxin-1 inhibitor, have been shown to disrupt thioredoxin-mediated redox signaling and decrease the proliferation and clonogenicity of MM cells by inhibiting TrxR1/2 and Trx2, respectively.

In addition, depletion of intracellular GSH may account for increased cellular susceptibility to oxidative stress and 


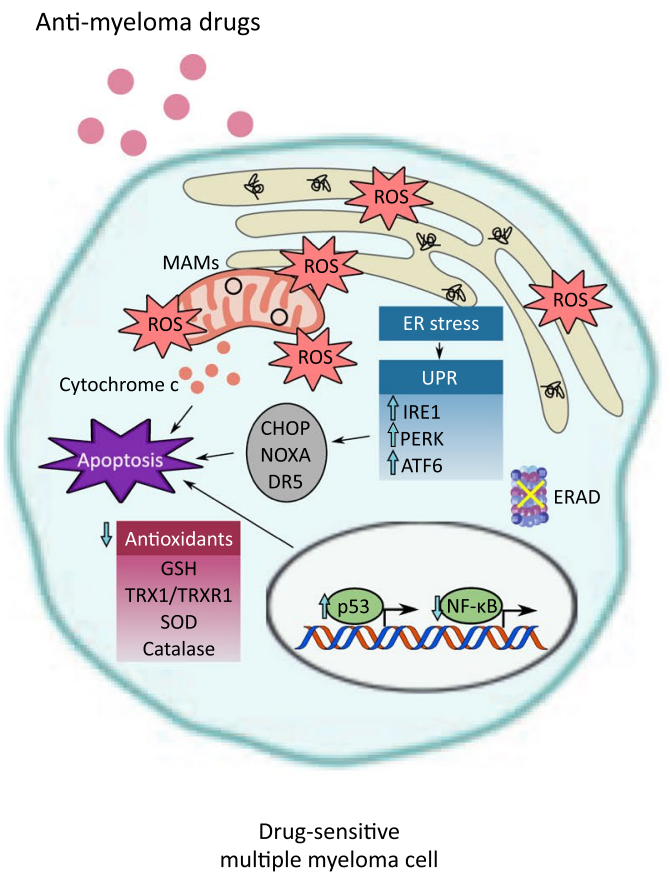

Fig. 3 Differences between drug-sensitive and -resistant multiple myeloma cells. Anti-myeloma drug, such as proteasome inhibitor, induces apoptosis through multiple mechanisms, such as disruption of normal protein turnover by amino acid depletion, inhibition of ERAD, activation of UPR-mediated apoptosis signaling (e.g., CHOP, NOXA, DR5), induction of mitochondrial damage with increased $\mathrm{Ca}^{2+}$ transfer to the mitochondria at the MAM and reduction in

reduced drug accumulation in target cells. GSH binds covalently to the trivalent form of arsenic, such as $\mathrm{As}_{2} \mathrm{O}_{3}$, and subsequently promotes drug extrusion through efflux pumps [256, 257]. In combination therapies containing GSH-depleting agents such as ascorbic acid, $\mathrm{As}_{2} \mathrm{O}_{3}$ has demonstrated beneficial clinical effects in inducing remission in $\mathrm{MM}$ patients, but $\mathrm{As}_{2} \mathrm{O}_{3}$ alone has limited efficacy. This implies that cellular GSH level plays a critical role in $\mathrm{As}_{2} \mathrm{O}_{3}$-induced apoptosis that impairs mitochondrial respiration and uncouples oxidative phosphorylation [258].

Inhibition of enzymatic antioxidant metalloprotein SOD, such as copper-zinc SOD (CuZnSOD/SOD1), using bivalent metal-ion chelator DSF and diethyldithiocarbamate (DDC) has been shown to enhance the cytotoxicity of proteasome inhibitors in drug-resistant cells [259]. Mice deficient in CuZnSOD were found to have heightened cellular oxidative damage and reduced GPX and mitochondria-resident manganese SOD (MnSOD) activities [260]. The formation of DSF/Cu complex suppresses MEK1 activation and induces apoptosis by restricting the availability of $\mathrm{Cu}$ to enhance MEK1 phosphorylation of ERK1/2 [261]. DSF and DDC are also known to inhibit aldehyde dehydrogenase (ALDH), a family of NADP-dependent enzymes associated with detoxification of reactive aldehydes, retinoic acid synthesis and

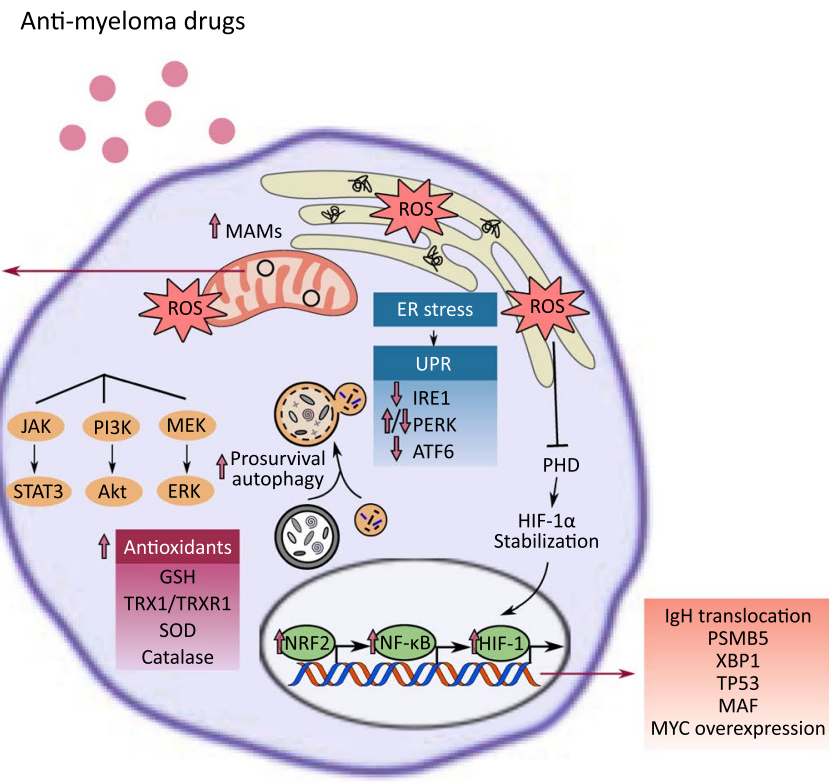

$$
\begin{gathered}
\text { Drug-resistant } \\
\text { multiple myeloma cell }
\end{gathered}
$$

antioxidant defense. Myeloma cells may acquire resistance through genetic mutations and/or transcriptional controls. This leads to downregulation of dependence on the UPR and upregulation of signaling pathways contributing to redox homeostasis, cellular survival and transition into quiescent state. NOXA/PMAIP1 phorbol-12-Myristate13-Acetate-Induced Protein 1, DR5 death receptor 5

drug tolerance, highly expressed in MM. DSF can eliminate a relapse-inducing subpopulation of $\mathrm{ALDH}^{\text {high }}$ stem-cell like MM cells by downregulating stemness transcription factors NANOG and OCT4 [262].

\section{Discussion and perspectives}

Elevated ER stress response and aberrant redox status are classic hallmarks of MM cells. Emerging studies have provided promising insight into the intricate relationships between UPR, oxidative stress and survival pathways prominent in MM. Excessive production of immunoglobulin and several cytokines promotes ROS generation as a by-product of protein folding and mitochondrial energy metabolism, and activates numerous cytoprotective mechanisms that enable MM cells to evade from anti-myeloma therapies through elevation of ROS scavenging activities and further induction of UPR-related pathways. The discovery of regulatory nodes in the intracellular protein and redox homeostasis network and novel roles of ER stress sentinels may unveil potential anti-myeloma therapeutic targets to eliminate drug-resistant sub-clones while minimizing toxicity toward normal plasma cells. 
Table 1 List of promising anti-myeloma drugs targeting UPR \& redox regulatory systems

\begin{tabular}{|c|c|c|c|}
\hline Drug/treatment & Mechanism of action & Phase/status & $\begin{array}{l}\text { References/identifier trial number } \\
\text { (https://clinicaltrials.gov/) }\end{array}$ \\
\hline \multicolumn{4}{|l|}{ ER-stress-inducing agents targeting UPR } \\
\hline GSK2606414 & Inhibits PERK, $\downarrow$ phospho-eIF2 $\alpha$ & Preclinical & [263] \\
\hline GSK2656157 & \multirow{4}{*}{$\begin{array}{l}\text { Inhibits IRE1 } \alpha \text { RNase activity, } \downarrow \\
\quad \text { XBP1 }\end{array}$} & Preclinical & [264] \\
\hline MKC-3946 & & Preclinical & {$[15]$} \\
\hline STF-083010 & & Preclinical & {$[265]$} \\
\hline Toyocamycin & & Preclinical & [266] \\
\hline $4 \mu 8 \mathrm{C}$ & $\begin{array}{l}\text { Inhibits IRE1 } \alpha \text { RNase activity, } \downarrow \\
\text { XBP1 splicing, } \downarrow \text { RIDD }\end{array}$ & Preclinical & {$[267]$} \\
\hline CB-5083 & Inhibits ERAD & Phase I/terminated & NCT02223598 [268, 269] \\
\hline PAT-SM6 & Inhibits GRP78 & Phase I/completed & NCT01727778 \\
\hline \multirow[t]{2}{*}{ ONC201 } & \multirow[t]{2}{*}{$\uparrow$ phospho-eIF $2 \alpha, \uparrow$ ATF $4, \uparrow$ CHOP } & Phase I/II/ongoing & NCT02863991 \\
\hline & & Phase I/recruiting & NCT02609230 \\
\hline Sunitinib malate & $\begin{array}{l}\downarrow \text { XBP1 splicing, } \downarrow \text { VEGFR, } \downarrow \\
\text { PDGFR }\end{array}$ & Phase II/completed & NCT00514137 \\
\hline \multicolumn{4}{|c|}{ ROS-inducing agents targeting thioredoxin system } \\
\hline Auranofin & $\begin{array}{l}\text { Inhibits TrxR1/2, } \downarrow \text { STAT3, } \downarrow \text { NF- } \kappa B \text {, } \\
\uparrow \text { ROS }\end{array}$ & Preclinical & {$[218,270]$} \\
\hline PX-12 & $\begin{array}{l}\text { Inhibits Trx1, } \downarrow \text { HIF-1 } \alpha, \downarrow \text { VEGF, } \uparrow \\
\quad \text { ROS }\end{array}$ & Preclinical & [217] \\
\hline \multicolumn{4}{|c|}{ ROS-inducing agents targeting glutaredoxin system } \\
\hline Formononetin & $\downarrow$ STAT3/5, $\downarrow$ GSH, $\uparrow$ GSSG,$\uparrow$ ROS & Preclinical & {$[271]$} \\
\hline GO-203 & $\begin{array}{l}\downarrow \text { MUC1-C }, \downarrow \text { TIGAR, } \downarrow \text { NADPH }, \downarrow \\
\text { GSH }, \uparrow \text { ROS }\end{array}$ & Preclinical & [109] \\
\hline Imexon & $\downarrow \mathrm{GSH}, \uparrow \mathrm{ROS}, \uparrow$ caspase- $8 / 9$ & Phase II/completed & NCT00327249 \\
\hline $\mathrm{As}_{2} \mathrm{O}_{3}+\mathrm{AA}$ & $\downarrow \mathrm{GSH}, \uparrow \mathrm{ROS}, \downarrow \mathrm{NF}-\kappa \mathrm{B}, \uparrow \mathrm{JNK}, \uparrow$ & Phase I/II/completed & [256] \\
\hline $\mathrm{As}_{2} \mathrm{O}_{3}+\mathrm{AA}+$ Bortezomib & p38 MAP kinase & Phase I/II/completed & {$[272]$} \\
\hline $\begin{array}{l}\mathrm{As}_{2} \mathrm{O}_{3}+\mathrm{AA}+\text { Bortezomib }+ \text { Mel- } \\
\text { phalan }\end{array}$ & & Phase II/completed & NCT00469209 \\
\hline $\mathrm{As}_{2} \mathrm{O}_{3}+\mathrm{AA}+$ Melphalan & & Phase II/completed & NCT00661544 \\
\hline \multicolumn{4}{|c|}{ ROS-inducing agents targeting SOD and/or catalase } \\
\hline Parthenolide & $\begin{array}{l}\downarrow \text { Catalase, } \downarrow \text { MnSOD, } \downarrow \text { NF-кB, } \uparrow \\
\quad \text { ROS }\end{array}$ & Preclinical & {$[273]$} \\
\hline DSF & $\begin{array}{l}\downarrow \text { CuZnSOD }, \downarrow \text { ALDH1A1, } \downarrow \text { Gli1/2, } \\
\quad \uparrow \text { ROS }\end{array}$ & Preclinical & {$[259,262]$} \\
\hline $\begin{array}{l}\text { Diethyldithiocarbamate } \\
\text { (DDC) + Lanalidomide/Pomalido- } \\
\text { mide }\end{array}$ & $\downarrow \mathrm{CuZnSOD}, \uparrow \mathrm{ROS}$ & Phase NA/not yet recruiting & NCT04234022 \\
\hline \multicolumn{4}{|l|}{ Other ROS-inducing agents } \\
\hline Sulindac & $\uparrow$ p38 MAP kinase,$\uparrow$ ROS & Preclinical & {$[274]$} \\
\hline \multicolumn{4}{|l|}{ Hypoxia-activated prodrug } \\
\hline $\begin{array}{l}\text { Evofosfamide }(\mathrm{TH}-302)+\text { Dexa- } \\
\text { methasone } \pm \text { Bortezomib }\end{array}$ & $\begin{array}{l}\downarrow \text { cyclinD } 1 / 2 / 3, \downarrow \text { CDK } 4 / 6 \\
\downarrow \text { p } 21^{\text {cip }-1}, \downarrow \mathrm{p} 27^{\text {kip }-1}, \downarrow \mathrm{pRb}, \\
\uparrow \text { caspase- } 3 / 8 / 9\end{array}$ & Phase I/II/completed & NCT01522872 \\
\hline
\end{tabular}

Selected preclinical and clinical studies

VEGFR Vascular Endothelial Growth Factor Receptors, PDGFR Platelet-derived growth factor receptor, STAT3/5 Signal transducer and activator of transcription 3/5, MUC1-C Mucin 1 transmembrane C-terminal, TIGAR TP53 induced glycolysis regulatory phosphatase, MnSOD Manganese superoxide dismutase, $C u Z n S O D$ Copper-zinc-superoxide dismutase, ALDH1A1 Aldehyde dehydrogenase 1 family member A1, Gli1/2 Glioma-associated oncogene homologue $1 / 2, C D K 4 / 6$ Cyclin-dependent kinase $4 / 6, p 21^{c i p-l}$ Cyclin-dependent kinase inhibitor $1, p 27^{k i p-l}$ Cyclindependent kinase inhibitor $1 \mathrm{~B}, p R b$ Retinoblastoma protein 
Individualized therapeutic strategy focused on genetic and epigenetic basis of drug response variability among patients with MM may guide clinical decision making. The selective pressure imposed by treatments and the complex hypoxic tumor microenvironment may lead to the divergent evolution of quiescent tumor-initiating MM cells with drug resistance-conferring aberrations, necessitating an in-depth understanding of the evolution patterns of drug resistance for advanced development of therapeutic modalities against MM.

\section{Acknowledgements Not applicable.}

Author contributions SX, JZ and WJC all reviewed the literature and wrote the manuscript. All authors have read and approved the final manuscript.

Funding This work was supported by the Singapore National Research Foundation and the Ministry of Education under the Research Center of Excellence Program to WJ Chng. W.J.C. is also supported by NMRC Clinician Scientist Investigator award. This study is also partially supported by the RNA Biology Center at CSI Singapore, NUS, from funding by the Singapore Ministry of Education's Tier 3 grants, grant number MOE2014-T3-1-006.

\section{Compliance with ethical standards}

Conflict of interest The authors declare that they have no competing interests.

Open Access This article is licensed under a Creative Commons Attribution 4.0 International License, which permits use, sharing, adaptation, distribution and reproduction in any medium or format, as long as you give appropriate credit to the original author(s) and the source, provide a link to the Creative Commons licence, and indicate if changes were made. The images or other third party material in this article are included in the article's Creative Commons licence, unless indicated otherwise in a credit line to the material. If material is not included in the article's Creative Commons licence and your intended use is not permitted by statutory regulation or exceeds the permitted use, you will need to obtain permission directly from the copyright holder. To view a copy of this licence, visit http://creativecommons.org/licenses/by/4.0/.

\section{References}

1. Cid Ruzafa J, Merinopoulou E, Baggaley RF, Leighton P, Werther W, Felici D, Cox A (2016) Patient population with multiple myeloma and transitions across different lines of therapy in the USA: an epidemiologic model. Pharmacoepidemiol Drug Saf 25(8):871-879

2. Howlader N, Noone A, Krapcho M, Miller D, Brest A, Yu M, Ruhl J, Tatalovich Z, Mariotto A, Lewis D, Chen H, Feuer E, Cronin K SEER Cancer Statistics Review, 1975-2017. National Cancer Institute. 2019. https://seer.cancer.gov/csr/1975 2017/. Accessed 12 April 2020

3. Labbadia J, Morimoto RI (2015) The biology of proteostasis in aging and disease. Annu Rev Biochem 84:435-464
4. Loaiza S, Ferreira SA, Chinn TM, Kirby A, Tsolaki E, Dondi C, Parzych K, Strange AP, Bozec L, Bertazzo S (2018) An engineered, quantifiable in vitro model for analysing the effect of proteostasis-targeting drugs on tissue physical properties. Biomaterials 183:102-113

5. Saavedra-García P, Martini F, Auner HW (2020) Proteasome inhibition in multiple myeloma: lessons for other cancers. Am J Physiol-Cell Physiol 318(3):C451-C462

6. Shimizu Y, Hendershot LM (2009) Oxidative folding: cellular strategies for dealing with the resultant equimolar production of reactive oxygen species. Antioxid Redox Signal 11(9):2317-2331

7. Wang J, Pareja KA, Kaiser CA, Sevier CS (2014) Redox signaling via the molecular chaperone $\mathrm{BiP}$ protects cells against endoplasmic reticulum-derived oxidative stress. Elife 3:e03496

8. Krishnan N, Fu C, Pappin DJ, Tonks NK (2011) H2S-Induced sulfhydration of the phosphatase PTP1B and its role in the endoplasmic reticulum stress response. Science signaling 4(203):ra86-ra86

9. Hourihan JM, Mazzeo LEM, Fernández-Cárdenas LP, Blackwell TK (2016) Cysteine sulfenylation directs IRE-1 to activate the SKN-1/Nrf2 antioxidant response. Mol Cell 63(4):553-566

10. Chapman MA, Lawrence MS, Keats JJ, Cibulskis K, Sougnez C, Schinzel AC, Harview CL, Brunet J-P, Ahmann GJ, Adli M (2011) Initial genome sequencing and analysis of multiple myeloma. Nature 471(7339):467-472

11. Nikesitch N, Lee JM, Ling S, Roberts TL (2018) Endoplasmic reticulum stress in the development of multiple myeloma and drug resistance. Clin Translat Immunol 7(1):e1007

12. White-Gilbertson S, Hua Y, Liu B (2013) The role of endoplasmic reticulum stress in maintaining and targeting multiple myeloma: a double-edged sword of adaptation and apoptosis. Front Genet 4:109

13. Logue SE, McGrath EP, Cleary P, Greene S, Mnich K, Almanza A, Chevet E, Dwyer RM, Oommen A, Legembre P (2018) Inhibition of IRE1 RNase activity modulates the tumor cell secretome and enhances response to chemotherapy. Nature Communications 9(1):1-14

14. Madden E, Logue SE, Healy SJ, Manie S, Samali A (2019) The role of the unfolded protein response in cancer progression: from oncogenesis to chemoresistance. Biol Cell 111(1):1-17

15. Mimura N, Fulciniti M, Gorgun G, Tai Y-T, Cirstea D, Santo L, Hu Y, Fabre C, Minami J, Ohguchi H (2012) Blockade of $\mathrm{XBP} 1$ splicing by inhibition of IRE1 $\alpha$ is a promising therapeutic option in multiple myeloma. Blood, The J Am Soc Hematol 119(24):5772-5781

16. Tang C-HA, Ranatunga S, Kriss CL, Cubitt CL, Tao J, Pinilla-Ibarz JA, Del Valle JR, Hu C-CA (2014) Inhibition of ER stress-associated IRE-1/XBP-1 pathway reduces leukemic cell survival. J Clin Investig 124(6):2585-2598

17. Hollien J, Weissman JS (2006) Decay of endoplasmic reticulum-localized mRNAs during the unfolded protein response. Science 313(5783):104-107

18. Lee A-H, Iwakoshi NN, Glimcher LH (2003) XBP-1 regulates a subset of endoplasmic reticulum resident chaperone genes in the unfolded protein response. Mol Cell Biol 23(21):7448-7459

19. Yoshida H, Matsui T, Hosokawa N, Kaufman RJ, Nagata K, Mori K (2003) A time-dependent phase shift in the mammalian unfolded protein response. Dev Cell 4(2):265-271

20. Gupta S, Deepti A, Deegan S, Lisbona F, Hetz C, Samali A (2010) HSP72 protects cells from ER stress-induced apoptosis via enhancement of IRE1 $\alpha$-XBP1 signaling through a physical interaction. PLoS Biol 8(7):e1000410

21. Mitsiades N, Mitsiades CS, Poulaki V, Chauhan D, Fanourakis G, Gu X, Bailey C, Joseph M, Libermann TA, Treon SP (2002) 
Molecular sequelae of proteasome inhibition in human multiple myeloma cells. Proc Natl Acad Sci 99(22):14374-14379

22. Davenport EL, Moore HE, Dunlop AS, Sharp SY, Workman P, Morgan GJ, Davies FE (2007) Heat shock protein inhibition is associated with activation of the unfolded protein response pathway in myeloma plasma cells. Blood, The J Am Soc Hematol 110(7):2641-2649

23. Marcu MG, Doyle M, Bertolotti A, Ron D, Hendershot L, Neckers L (2002) Heat shock protein 90 modulates the unfolded protein response by stabilizing IRE1 $\alpha$. Mol Cell Biol 22(24):8506-8513

24. Bagratuni T, Wu P, Gonzalez de Castro D, Davenport EL, Dickens NJ, Walker BA, Boyd K, Johnson DC, Gregory W, Morgan GJ (2010) XBP1s levels are implicated in the biology and outcome of myeloma mediating different clinical outcomes to thalidomide-based treatments. Blood, The J Am Soc Hematol 116(2):250-253

25. Gambella M, Rocci A, Passera R, Gay F, Omedè P, Crippa C, Corradini P, Romano A, Rossi D, Ladetto M (2014) High XBP1 expression is a marker of better outcome in multiple myeloma patients treated with bortezomib. Haematologica 99(2):e14-e16

26. Ling SC, Lau EK, Al-Shabeeb A, Nikolic A, Catalano A, Iland H, Horvath N, Ho PJ, Harrison S, Fleming S (2012) Response of myeloma to the proteasome inhibitor bortezomib is correlated with the unfolded protein response regulator XBP-1. Haematologica 97(1):64-72

27. Leung-Hagesteijn C, Erdmann N, Cheung G, Keats JJ, Stewart AK, Reece DE, Chung KC, Tiedemann RE (2013) Xbp1s-negative tumor $B$ cells and pre-plasmablasts mediate therapeutic proteasome inhibitor resistance in multiple myeloma. Cancer Cell 24(3):289-304

28. Hong SY, Hagen T (2013) Multiple myeloma Leu167Ile (c.499C $>$ A) mutation prevents XBP1 mRNA splicing. British J Haematol 161(6):898-901. https://doi.org/10.1111/bjh.12310

29. Brewer JW (2014) Regulatory crosstalk within the mammalian unfolded protein response. Cell Mol Life Sci 71(6):1067-1079

30. Hollien J, Lin JH, Li H, Stevens N, Walter P, Weissman JS (2009) Regulated Ire1-dependent decay of messenger RNAs in mammalian cells. J Cell Biol 186(3):323-331

31. Chen Y, Brandizzi F (2013) IRE1: ER stress sensor and cell fate executor. Trends Cell Biol 23(11):547-555

32. Sakaki K, Yoshina S, Shen X, Han J, DeSantis MR, Xiong M, Mitani S, Kaufman RJ (2012) RNA surveillance is required for endoplasmic reticulum homeostasis. Proc Natl Acad Sci 109(21):8079-8084

33. Matsuzawa A, Nishitoh $\mathrm{H}$, Tobiume K, Takeda K, Ichijo $\mathrm{H}$ (2002) Physiological roles of ASK1-mediated signal transduction in oxidative stress-and endoplasmic reticulum stress-induced apoptosis: advanced findings from ASK1 knockout mice. Antioxid Redox Signal 4(3):415-425

34. Tobiume K, Matsuzawa A, Takahashi T, Nishitoh H, Ki M, Takeda K, Minowa O, Miyazono K, Noda T, Ichijo H (2001) ASK1 is required for sustained activations of JNK/p38 MAP kinases and apoptosis. EMBO Rep 2(3):222-228

35. Ichijo H, Nishida E, Irie K, ten Dijke P, Saitoh M, Moriguchi T, Takagi M, Matsumoto K, Miyazono K, Gotoh Y (1997) Induction of apoptosis by ASK1, a mammalian MAPKKK that activates SAPK/JNK and p38 signaling pathways. Science 275(5296):90-94

36. Saitoh M, Nishitoh H, Fujii M, Takeda K, Tobiume K, Sawada Y, Kawabata M, Miyazono K, Ichijo H (1998) Mammalian thioredoxin is a direct inhibitor of apoptosis signal-regulating kinase (ASK) 1. The EMBO journal 17(9):2596-2606
37. Soga M, Matsuzawa A, Ichijo H (2012) Oxidative stressinduced diseases via the ASK1 signaling pathway. Int J Cell Biol 2012:439587. https://doi.org/10.1155/2012/439587

38. Fels DR, Koumenis C (2006) The PERK/eIF2 $\alpha /$ ATF4 module of the UPR in hypoxia resistance and tumor growth. Cancer Biol Ther 5(7):723-728

39. Rajesh K, Krishnamoorthy J, Kazimierczak U, Tenkerian C, Papadakis A, Wang S, Huang S, Koromilas A (2015) Phosphorylation of the translation initiation factor eIF2 $\alpha$ at serine 51 determines the cell fate decisions of Akt in response to oxidative stress. Cell Death Dis 6(1):e1591-e1591

40. Alam J, Stewart D, Touchard C, Boinapally S, Choi AM, Cook JL (1999) Nrf2, a Cap'n'Collar transcription factor, regulates induction of the heme oxygenase-1 gene. J Biol Chem 274(37):26071-26078

41. Michallet A-S, Mondiere P, Taillardet M, Leverrier Y, Genestier L, Defrance T (2011) Compromising the unfolded protein response induces autophagy-mediated cell death in multiple myeloma cells. PLoS ONE 6(10):e25820

42. Ma Y, Shimizu Y, Mann MJ, Jin Y, Hendershot LM (2010) Plasma cell differentiation initiates a limited ER stress response by specifically suppressing the PERK-dependent branch of the unfolded protein response. Cell Stress Chaperones 15(3):281-293

43. Tibullo D, Barbagallo I, Giallongo C, Vanella L, Conticello C, Romano A, Saccone S, Godos J, Di Raimondo F, Volti GL (2016) Heme oxygenase-1 nuclear translocation regulates bortezomib-induced cytotoxicity and mediates genomic instability in myeloma cells. Oncotarget 7(20):28868

44. Riz I, Hawley TS, Marsal JW, Hawley RG (2016) Noncanonical SQSTM1/p62-Nrf2 pathway activation mediates proteasome inhibitor resistance in multiple myeloma cells via redox, metabolic and translational reprogramming. Oncotarget 7(41):66360

45. Wang X, Campos CR, Peart JC, Smith LK, Boni JL, Cannon RE, Miller DS (2014) Nrf2 upregulates ATP binding cassette transporter expression and activity at the blood-brain and bloodspinal cord barriers. J Neurosci 34(25):8585-8593

46. Harding HP, Zhang Y, Zeng H, Novoa I, Lu PD, Calfon M, Sadri N, Yun C, Popko B, Paules R (2003) An integrated stress response regulates amino acid metabolism and resistance to oxidative stress. Mol Cell 11(3):619-633

47. Lewerenz J, Maher P (2009) Basal levels of eIF2 $\alpha$ phosphorylation determine cellular antioxidant status by regulating ATF4 and xCT expression. J Biol Chem 284(2):1106-1115

48. Rozpedek W, Pytel D, Mucha B, Leszczynska H, Diehl JA, Majsterek I (2016) The role of the PERK/eIF2 $\alpha /$ ATF4/CHOP signaling pathway in tumor progression during endoplasmic reticulum stress. Curr Mol Med 16(6):533-544

49. Han J, Back SH, Hur J, Lin Y-H, Gildersleeve R, Shan J, Yuan CL, Krokowski D, Wang S, Hatzoglou M (2013) ER-stressinduced transcriptional regulation increases protein synthesis leading to cell death. Nat Cell Biol 15(5):481-490

50. Hu H, Tian M, Ding C, Yu S (2019) The C/EBP homologous protein (CHOP) transcription factor functions in endoplasmic reticulum stress-induced apoptosis and microbial infection. Front Immunol 9:3083

51. Obeng EA, Carlson LM, Gutman DM, Harrington WJ, Lee KP, Boise LH (2006) Proteasome inhibitors induce a terminal unfolded protein response in multiple myeloma cells. Blood 107(12):4907-4916

52. Burwick N, Zhang MY, de la Puente P, Azab AK, Hyun TS, Ruiz-Gutierrez M, Sanchez-Bonilla M, Nakamura T, Delrow JJ, MacKay VL (2017) The eIF2-alpha kinase HRI is a novel therapeutic target in multiple myeloma. Leuk Res 55:23-32 
53. Koumenis C, Wouters BG (2006) “Translating” tumor hypoxia: unfolded protein response (UPR) - dependent and UPR-independent pathways. Mol Cancer Res 4(7):423-436

54. Martinon F, Glimcher LH (2011) Regulation of innate immunity by signaling pathways emerging from the endoplasmic reticulum. Curr Opin Immunol 23(1):35-40

55. Gass JN, Gifford NM, Brewer JW (2002) Activation of an unfolded protein response during differentiation of antibodysecreting B cells. J Biol Chem 277(50):49047-49054

56. Haze K, Yoshida H, Yanagi H, Yura T, Mori K (1999) Mammalian transcription factor ATF6 is synthesized as a transmembrane protein and activated by proteolysis in response to endoplasmic reticulum stress. Mol Biol Cell 10(11):3787-3799

57. Namba T, Ishihara T, Tanaka K-i, Hoshino T, Mizushima $T$ (2007) Transcriptional activation of ATF6 by endoplasmic reticulum stressors. Biochem Biophys Res Commun 355(2):543-548

58. Okada T, Yoshida H, Akazawa R, Negishi M, Mori K (2002) Distinct roles of activating transcription factor 6 (ATF6) and double-stranded RNA-activated protein kinase-like endoplasmic reticulum kinase (PERK) in transcription during the mammalian unfolded protein response. Biochemical Journal 366(2):585-594

59. Wang Y, Shen J, Arenzana N, Tirasophon W, Kaufman RJ, Prywes R (2000) Activation of ATF6 and an ATF6 DNA binding site by the endoplasmic reticulum stress response. J Biol Chem 275(35):27013-27020

60. Lee K, Tirasophon W, Shen X, Michalak M, Prywes R, Okada T, Yoshida H, Mori K, Kaufman RJ (2002) IRE1-mediated unconventional mRNA splicing and S2P-mediated ATF6 cleavage merge to regulate XBP1 in signaling the unfolded protein response. Genes Dev 16(4):452-466

61. Yoshida H, Matsui T, Yamamoto A, Okada T, Mori K (2001) XBP1 mRNA is induced by ATF6 and spliced by IRE1 in response to ER stress to produce a highly active transcription factor. Cell 107(7):881-891

62. Nikesitch N, Tao C, Lai K, Killingsworth M, Bae S, Wang M, Harrison S, Roberts TL, Ling S (2016) Predicting the response of multiple myeloma to the proteasome inhibitor Bortezomib by evaluation of the unfolded protein response. Blood Cancer $\mathbf{J}$ 6(6):e432-e432

63. Manz RA, Arce S, Cassese G, Hauser AE, Hiepe F, Radbruch A (2002) Humoral immunity and long-lived plasma cells. Curr Opin Immunol 14(4):517-521

64. Chu VT, Berek C (2013) The establishment of the plasma cell survival niche in the bone marrow. Immunol Rev 251(1):177-188

65. Manier S, Sacco A, Leleu X, Ghobrial IM, Roccaro AM (2012) Bone marrow microenvironment in multiple myeloma progression. J Biomed Biotechnol 2012:157496. https://doi. org/10.1155/2012/157496

66. Rozanski CH, Arens R, Carlson LM, Nair J, Boise LH, ChananKhan AA, Schoenberger SP, Lee KP (2011) Sustained antibody responses depend on $\mathrm{CD} 28$ function in bone marrow-resident plasma cells. J Exp Med 208(7):1435-1446

67. Bahlis NJ, King AM, Kolonias D, Carlson LM, Liu HY, Hussein MA, Terebelo HR, Byrne GE, Levine BL, Boise LH (2007) CD28-mediated regulation of multiple myeloma cell proliferation and survival. Blood 109(11):5002-5010

68. Lam WY, Bhattacharya D (2018) Metabolic links between plasma cell survival, secretion, and stress. Trends Immunol 39(1):19-27

69. Auner HW, Beham-Schmid C, Dillon N, Sabbattini P (2010) The life span of short-lived plasma cells is partly determined by a block on activation of apoptotic caspases acting in combination with endoplasmic reticulum stress. Blood, The J Am Soc Hematol 116(18):3445-3455

70. Cenci S, Mezghrani A, Cascio P, Bianchi G, Cerruti F, Fra A, Lelouard H, Masciarelli S, Mattioli L, Oliva L (2006)
Progressively impaired proteasomal capacity during terminal plasma cell differentiation. The EMBO journal 25(5):1104-1113

71. Pelletier N, Casamayor-Pallejà $M$, De Luca K, Mondière $P$, Saltel F, Jurdic P, Bella C, Genestier L, Defrance T (2006) The endoplasmic reticulum is a key component of the plasma cell death pathway. J Immunol 176(3):1340-1347

72. Low MSY, Brodie EJ, Fedele PL, Liao Y, Grigoriadis G, Strasser A, Kallies A, Willis SN, Tellier J, Shi W (2019) IRF4 activity is required in established plasma cells to regulate gene transcription and mitochondrial homeostasis. Cell Reports 29(9):2634-2645 ((e2635))

73. De Silva NS, Simonetti G, Heise N, Klein U (2012) The diverse roles of IRF4 in late germinal center B-cell differentiation. Immunol Rev 247(1):73-92

74. Calfon M, Zeng H, Urano F, Till JH, Hubbard SR, Harding HP, Clark SG, Ron D (2002) IRE1 couples endoplasmic reticulum load to secretory capacity by processing the XBP-1 mRNA. Nature 415(6867):92-96

75. Reimold AM, Iwakoshi NN, Manis J, Vallabhajosyula P, Szomolanyi-Tsuda E, Gravallese EM, Friend D, Grusby MJ, Alt F, Glimcher LH (2001) Plasma cell differentiation requires the transcription factor XBP-1. Nature 412(6844):300-307

76. Tellier J, Shi W, Minnich M, Liao Y, Crawford S, Smyth GK, Kallies A, Busslinger M, Nutt SL (2016) Blimp-1 controls plasma cell function through the regulation of immunoglobulin secretion and the unfolded protein response. Nat Immunol 17(3):323-330

77. Gass JN, Jiang H-Y, Wek RC, Brewer JW (2008) The unfolded protein response of B-lymphocytes: PERK-independent development of antibody-secreting cells. Mol Immunol 45(4):1035-1043

78. Drori A, Tirosh B (2011) Regulation of immunoglobulin synthesis, modification, and trafficking by the unfolded protein response a quantitative approach. Methods in enzymology, vol 491. Elsevier, Germany, pp 309-325

79. Van Anken E, Romijn EP, Maggioni C, Mezghrani A, Sitia R, Braakman I, Heck AJ (2003) Sequential waves of functionally related proteins are expressed when B cells prepare for antibody secretion. Immunity 18(2):243-253

80. Shoulders MD, Ryno LM, Genereux JC, Moresco JJ, Tu PG, Wu C, Yates JR III, Su AI, Kelly JW, Wiseman RL (2013) Stressindependent activation of XBP1s and/or ATF6 reveals three functionally diverse ER proteostasis environments. Cell reports 3(4):1279-1292

81. Zhang K, Wong HN, Song B, Miller CN, Scheuner D, Kaufman RJ (2005) The unfolded protein response sensor IRE1 $\alpha$ is required at 2 distinct steps in B cell lymphopoiesis. J Clin Investig 115(2):268-281

82. Ciechanover A (2005) Proteolysis: from the lysosome to ubiquitin and the proteasome. Nat Rev Mol Cell Biol 6(1):79-87

83. Milan E, Perini T, Resnati M, Orfanelli U, Oliva L, Raimondi A, Cascio P, Bachi A, Marcatti M, Ciceri F (2015) A plastic SQSTM1/p62-dependent autophagic reserve maintains proteostasis and determines proteasome inhibitor susceptibility in multiple myeloma cells. Autophagy 11(7):1161-1178

84. Zhu K, Dunner K, McConkey DJ (2010) Proteasome inhibitors activate autophagy as a cytoprotective response in human prostate cancer cells. Oncogene 29(3):451-462

85. Sánchez-Martín P, Ys S, Kageyama S, Koike M, Waguri S, Komatsu M (2020) NBR 1-mediated p62-liquid droplets enhance the Keap1-Nrf2 system. EMBO Rep 21(3):e48902

86. Yang Y, Willis TL, Button RW, Strang CJ, Fu Y, Wen X, Grayson PR, Evans T, Sipthorpe RJ, Roberts SL (2019) Cytoplasmic DAXX drives SQSTM1/p62 phase condensation to activate Nrf2-mediated stress response. Nature communications 10(1):1-18 
87. Suraweera A, Münch C, Hanssum A, Bertolotti A (2012) Failure of amino acid homeostasis causes cell death following proteasome inhibition. Mol Cell 48(2):242-253

88. Kawaguchi T, Miyazawa K, Moriya S, Ohtomo T, Che X-F, Naito M, Itoh M, Tomoda A (2011) Combined treatment with bortezomib plus bafilomycin A1 enhances the cytocidal effect and induces endoplasmic reticulum stress in U266 myeloma cells: crosstalk among proteasome, autophagy-lysosome and ER stress. Int J Oncol 38(3):643-654

89. Vogl DT, Stadtmauer EA, Tan K-S, Heitjan DF, Davis LE, Pontiggia L, Rangwala R, Piao S, Chang YC, Scott EC (2014) Combined autophagy and proteasome inhibition: a phase 1 trial of hydroxychloroquine and bortezomib in patients with relapsed/ refractory myeloma. Autophagy 10(8):1380-1390

90. Vabulas RM, Hartl FU (2005) Protein synthesis upon acute nutrient restriction relies on proteasome function. Science 310(5756): 1960-1963

91. Korolchuk VI, Mansilla A, Menzies FM, Rubinsztein DC (2009) Autophagy inhibition compromises degradation of ubiquitinproteasome pathway substrates. Mol Cell 33(4):517-527

92. Kouroku Y, Fujita E, Tanida I, Ueno T, Isoai A, Kumagai H, Ogawa S, Kaufman R, Kominami E, Momoi T (2007) ER stress (PERK/eIF2 $\alpha$ phosphorylation) mediates the polyglutamineinduced LC3 conversion, an essential step for autophagy formation. Cell Death Differ 14(2):230-239

93. Zheng W, Xie W, Yin D, Luo R, Liu M, Guo F (2019) ATG5 and ATG7 induced autophagy interplays with UPR via PERK signaling. Cell Commun Signaling 17(1):1-16

94. Ye J, Palm W, Peng M, King B, Lindsten T, Li MO, Koumenis C, Thompson CB (2015) GCN2 sustains mTORC1 suppression upon amino acid deprivation by inducing Sestrin2. Genes Dev 29(22):2331-2336

95. Jiang H-Y, Wek RC (2005) Phosphorylation of the $\alpha$-subunit of the eukaryotic initiation factor-2 (eIF2 $\alpha$ ) reduces protein synthesis and enhances apoptosis in response to proteasome inhibition. J Biol Chem 280(14):14189-14202

96. Jones DP (2006) Redefining oxidative stress. Antioxid Redox Signal 8(9-10):1865-1879

97. Espinosa-Diez C, Miguel V, Mennerich D, Kietzmann T, Sánchez-Pérez P, Cadenas S, Lamas S (2015) Antioxidant responses and cellular adjustments to oxidative stress. Redox biology 6:183-197

98. Kurutas EB (2015) The importance of antioxidants which play the role in cellular response against oxidative/nitrosative stress: current state. Nutr J 15(1):1-22

99. Hole PS, Zabkiewicz J, Munje C, Newton Z, Pearn L, White P, Marquez N, Hills RK, Burnett AK, Tonks A (2013) Overproduction of NOX-derived ROS in AML promotes proliferation and is associated with defective oxidative stress signaling. Blood, The J Am Soc Hematol 122(19):3322-3330

100. Mazor D, Abucoider A, Meyerstein N, Kapelushnik J (2008) Antioxidant status in pediatric acute lymphocytic leukemia (ALL) and solid tumors: the impact of oxidative stress. Pediatr Blood Cancer 51(5):613-615

101. Nieborowska-Skorska M, Kopinski PK, Ray R, Hoser G, Ngaba D, Flis S, Cramer K, Reddy MM, Koptyra M, Penserga T (2012) Rac2-MRC-cIII-generated ROS cause genomic instability in chronic myeloid leukemia stem cells and primitive progenitors. Blood, The J Am Soc Hematol 119(18):4253-4263

102. Gangemi S, Allegra A, Alonci A, Cristani M, Russo S, Speciale A, Penna G, Spatari G, Cannavò A, Bellomo G (2012) Increase of novel biomarkers for oxidative stress in patients with plasma cell disorders and in multiple myeloma patients with bone lesions. Inflamm Res 61(10):1063-1067
103. Zima T, Spicka I, Stipek S, Crkovska J, Platenik J, Merta M, Tesar V (1996) Antioxidant enzymes and lipid peroxidation in patients with multiple myeloma. Neoplasma 43(2):69-73

104. Sharma A, Tripathi M, Satyam A, Kumar L (2009) Study of antioxidant levels in patients with multiple myeloma. Leukemia Lymphoma 50(5):809-815

105. Al-Gayyar MM, Eissa LA, Rabie AM, El-Gayar AM (2007) Measurements of oxidative stress status and antioxidant activity in chronic leukaemia patients. J Pharm Pharmacol 59(3):409-417

106. Kodydkova J, Vavrova L, Stankova B, Macasek J, Krechler T, Zak A (2013) Antioxidant status and oxidative stress markers in pancreatic cancer and chronic pancreatitis. Pancreas 42(4):614-621

107. Akinloye O, Adaramoye O, Kareem O (2009) Changes in antioxidant status and lipid peroxidation in Nigerian patients with prostate carcinoma. Pol Arch Med Wewn 119(9):526-532

108. Pigeolet E, Corbisier P, Houbion A, Lambert D, Michiels C, Raes M, Zachary M-D, Remacle J (1990) Glutathione peroxidase, superoxide dismutase, and catalase inactivation by peroxides and oxygen derived free radicals. Mech Ageing Dev 51(3):283-297

109. Yin L, Kosugi M, Kufe D (2012) Inhibition of the MUC1-C oncoprotein induces multiple myeloma cell death by down-regulating TIGAR expression and depleting NADPH. Blood, The J Am Soc Hematol 119(3):810-816

110. Dytfeld D, Luczak M, Wrobel T, Usnarska-Zubkiewicz L, Brzezniakiewicz K, Jamroziak K, Giannopoulos K, Przybylowicz-Chalecka A, Ratajczak B, Czerwinska-Rybak J (2016) Comparative proteomic profiling of refractory/relapsed multiple myeloma reveals biomarkers involved in resistance to bortezomib-based therapy. Oncotarget 7(35):56726

111. Lipchick BC, Fink EE, Nikiforov MA (2016) Oxidative stress and proteasome inhibitors in multiple myeloma. Pharmacol Res 105:210-215

112. Bader M, Muse W, Ballou DP, Gassner C, Bardwell JC (1999) Oxidative protein folding is driven by the electron transport system. Cell 98(2):217-227

113. Tu BP, Weissman JS (2002) The FAD-and O2-dependent reaction cycle of Ero1-mediated oxidative protein folding in the endoplasmic reticulum. Mol Cell 10(5):983-994

114. Princiotta MF, Finzi D, Qian S-B, Gibbs J, Schuchmann S, Buttgereit F, Bennink JR, Yewdell JW (2003) Quantitating protein synthesis, degradation, and endogenous antigen processing. Immunity 18(3):343-354

115. Tu BP, Weissman JS (2004) Oxidative protein folding in eukaryotes mechanisms and consequences. J Cell Biol 164(3):341-346

116. May D, Itin A, Gal O, Kalinski H, Feinstein E, Keshet E (2005) Ero1-L $\alpha$ plays a key role in a HIF-1-mediated pathway to improve disulfide bond formation and VEGF secretion under hypoxia: implication for cancer. Oncogene 24(6):1011-1020

117. Tanaka T, Kutomi G, Kajiwara T, Kukita K, Kochin V, Kanaseki T, Tsukahara T, Hirohashi Y, Torigoe T, Okamoto Y (2017) Cancer-associated oxidoreductase ERO1- $\alpha$ promotes immune escape through up-regulation of PD-L1 in human breast cancer. Oncotarget 8(15):24706

118. Hayes KE, Batsomboon P, Chen W-C, Johnson BD, Becker A, Eschrich S, Yang Y, Robart AR, Dudley GB, Geldenhuys WJ (2019) Inhibition of the FAD containing ER oxidoreductin 1 (Ero1) protein by EN-460 as a strategy for treatment of multiple myeloma. Bioorg Med Chem 27(8):1479-1488

119. Takei N, Yoneda A, Sakai-Sawada K, Kosaka M, Minomi K, Tamura Y (2017) Hypoxia-inducible ERO1 $\alpha$ promotes cancer progression through modulation of integrin- $\beta 1$ modification and signalling in HCT116 colorectal cancer cells. Scientific reports 7(1):1-11 
120. Harmer D, Falank C, Reagan MR (2019) Interleukin-6 interweaves the bone marrow microenvironment, bone loss, and multiple myeloma. Front Endocrinol 9:788

121. Le Gouill S, Podar K, Amiot M, Hideshima T, Chauhan D, Ishitsuka K, Kumar S, Raje N, Richardson PG, Harousseau J-L (2004) VEGF induces Mcl-1 up-regulation and protects multiple myeloma cells against apoptosis. Blood 104(9):2886-2892

122. Soriano G, Besse L, Li N, Kraus M, Besse A, Meeuwenoord N, Bader J, Everts B, den Dulk H, Overkleeft H (2016) Proteasome inhibitor-adapted myeloma cells are largely independent from proteasome activity and show complex proteomic changes, in particular in redox and energy metabolism. Leukemia 30(11):2198-2207

123. Demasi APD, Martinez EF, Napimoga MH, Freitas LL, Vassallo J, Duarte ASS, Soares AB, Araujo NS, Araujo VC (2013) Expression of peroxiredoxins I and IV in multiple myeloma: association with immunoglobulin accumulation. Virchows Arch 463(1):47-55

124. Nguyen VD, Saaranen MJ, Karala A-R, Lappi A-K, Wang L, Raykhel IB, Alanen HI, Salo KE, Wang C-c, Ruddock LW (2011) Two endoplasmic reticulum PDI peroxidases increase the efficiency of the use of peroxide during disulfide bond formation. J Mol Biol 406(3):503-515

125. Schafer FQ, Buettner GR (2001) Redox environment of the cell as viewed through the redox state of the glutathione disulfide/ glutathione couple. Free Radical Biol Med 30(11):1191-1212

126. Chakravarthi S, Jessop CE, Bulleid NJ (2006) The role of glutathione in disulphide bond formation and endoplasmicreticulum-generated oxidative stress. EMBO Rep 7(3):271-275

127. Mulcahy RT, Bailey HH, Gipp JJ (1994) Up-regulation of $\gamma$-glutamylcysteine synthetase activity in melphalan-resistant human multiple myeloma cells expressing increased glutathione levels. Cancer Chemother Pharmacol 34(1):67-71

128. Starheim KK, Holien T, Misund K, Johansson I, Baranowska KA, Sponaas AM, Hella H, Buene G, Waage A, Sundan A (2016) Intracellular glutathione determines bortezomib cytotoxicity in multiple myeloma cells. Blood cancer journal 6(7):e446-e446

129. Fucci C, Resnati M, Riva E, Perini T, Ruggieri E, Orfanelli U, Paradiso F, Cremasco F, Raimondi A, Pasqualetto E (2020) The Interaction of the Tumor Suppressor FAM46C with p62 and FNDC3 Proteins Integrates Protein and Secretory Homeostasis. Cell Reports 32(12):108162

130. Mroczek S, Chlebowska J, Kuliński TM, Gewartowska O, Gruchota J, Cysewski D, Liudkovska V, Borsuk E, Nowis D, Dziembowski A (2017) The non-canonical poly (A) polymerase FAM46C acts as an onco-suppressor in multiple myeloma. Nature Commun 8(1):1-17

131. Zhu YX, Shi C-X, Bruins LA, Jedlowski P, Wang X, Kortüm KM, Luo M, Ahmann JM, Braggio E, Stewart AK (2017) Loss of FAM46C promotes cell survival in myeloma. Can Res 77(16):4317-4327

132. Townsend DM, Tew KD (2003) The role of glutathione$\mathrm{S}$-transferase in anti-cancer drug resistance. Oncogene 22(47):7369-7375

133. Davis RJ (2000) Signal transduction by the JNK group of MAP kinases. Inflammatory processes. Springer, Germany, pp 13-21

134. Ono K, Han J (2000) The p38 signal transduction pathway activation and function. Cell Signal 12(1):1-13

135. Zhang K, Mack P, Wong K (1998) Glutathione-related mechanisms in cellular resistance to anticancer drugs. Int $\mathrm{J}$ Oncol 12(4):871-953

136. Zmorzynski S, Popek-Marciniec S, Szudy-Szczyrek A, Wojcierowska-Litwin M, Korszen-Pilecka I, Chocholska S, Styk W, Hus M, Filip AA (2019) The association of GSTT1, GSTM1 and
TNF- $\alpha$ polymorphisms with the risk and outcome in multiple myeloma. Front Oncol 9:1056

137. Bedard K, Krause K-H (2007) The NOX family of ROS-generating NADPH oxidases: physiology and pathophysiology. Physiol Rev 87(1):245-313

138. Lambeth JD (2004) NOX enzymes and the biology of reactive oxygen. Nat Rev Immunol 4(3):181-189

139. Lambeth JD, Neish AS (2014) Nox enzymes and new thinking on reactive oxygen: a double-edged sword revisited. Annu Rev Pathol 9:119-145

140. Cheng G, Cao Z, Xu X, Van Meir EG, Lambeth JD (2001) Homologs of gp91phox: cloning and tissue expression of Nox3, Nox4, and Nox5. Gene 269(1-2):131-140

141. Bertolotti M, Farinelli G, Galli M, Aiuti A, Sitia R (2016) AQP8 transports NOX2-generated $\mathrm{H} 2 \mathrm{O} 2$ across the plasma membrane to promote signaling in B cells. J Leukoc Biol 100(5):1071-1079

142. Kobayashi S, Imajoh-Ohmi S, Nakamura M, Kanegasaki S (1990) Occurrence of cytochrome b558 in B-cell lineage of human lymphocytes. Blood 75(2):458-461. https://doi.org/10.1182/blood .V75.2.458.458

143. Sareila O, Kelkka T, Pizzolla A, Hultqvist M, Holmdahl R (2011) Nox2 complex-derived ROS as immune regulators. Antioxid Redox Signal 15(8):2197-2208

144. Richards SM, Clark EA (2009) BCR-induced superoxide negatively regulates B-cell proliferation and T-cell-independent type 2 Ab responses. Eur J Immunol 39(12):3395-3403

145. Wheeler ML, DeFranco AL (2012) Prolonged production of reactive oxygen species in response to $\mathrm{B}$ cell receptor stimulation promotes B cell activation and proliferation. J Immunol 189(9):4405-4416

146. Li G, Scull C, Ozcan L, Tabas I (2010) NADPH oxidase links endoplasmic reticulum stress, oxidative stress, and PKR activation to induce apoptosis. J Cell Biol 191(6):1113-1125

147. Pedruzzi E, Guichard C, Ollivier V, Driss F, Fay M, Prunet C, Marie J-C, Pouzet C, Samadi M, Elbim C (2004) NAD (P) H oxidase Nox-4 mediates 7-ketocholesterol-induced endoplasmic reticulum stress and apoptosis in human aortic smooth muscle cells. Mol Cell Biol 24(24):10703-10717

148. Chen K, Kirber MT, Xiao H, Yang Y, Keaney JF Jr (2008) Regulation of ROS signal transduction by NADPH oxidase 4 localization. The J Cell Biol 181(7):1129-1139

149. Panzhinskiy E, Hua Y, Culver B, Ren J, Nair S (2013) Endoplasmic reticulum stress upregulates protein tyrosine phosphatase 1B and impairs glucose uptake in cultured myotubes. Diabetologia 56(3):598-607

150. Yang M, Haase AD, Huang F-K, Coulis G, Rivera KD, Dickinson BC, Chang CJ, Pappin DJ, Neubert TA, Hannon GJ (2014) Dephosphorylation of tyrosine 393 in argonaute 2 by protein tyrosine phosphatase $1 \mathrm{~B}$ regulates gene silencing in oncogenic RAS-induced senescence. Mol Cell 55(5):782-790

151. Yip S-C, Saha S, Chernoff J (2010) PTP1B: a double agent in metabolism and oncogenesis. Trends Biochem Sci 35(8):442-449

152. Dubé N, Bourdeau A, Heinonen KM, Cheng A, Loy AL, Tremblay ML (2005) Genetic ablation of protein tyrosine phosphatase $1 \mathrm{~B}$ accelerates lymphomagenesis of p53-null mice through the regulation of B-cell development. Can Res 65(21):10088-10095

153. Le Sommer S, Morrice N, Pesaresi M, Thompson D, Vickers MA, Murray GI, Mody N, Neel BG, Bence KK, Wilson HM (2018) Deficiency in protein tyrosine phosphatase PTP1B shortens lifespan and leads to development of acute leukemia. Can Res 78(1):75-87

154. Zorov DB, Juhaszova M, Sollott SJ (2014) Mitochondrial reactive oxygen species (ROS) and ROS-induced ROS release. Physiol Rev 94(3):909-950

155. Tello D, Balsa E, Acosta-Iborra B, Fuertes-Yebra E, Elorza A, Ordóñez Á, Corral-Escariz M, Soro I, López-Bernardo E, 
Perales-Clemente E (2011) Induction of the mitochondrial NDUFA4L2 protein by HIF-1 $\alpha$ decreases oxygen consumption by inhibiting Complex I activity. Cell Metab 14(6):768-779

156. Williams GS, Boyman L, Chikando AC, Khairallah RJ, Lederer W (2013) Mitochondrial calcium uptake. Proc Natl Acad Sci 110(26):10479-10486

157. Brookes PS, Yoon Y, Robotham JL, Anders M, Sheu S-S (2004) Calcium, ATP, and ROS: a mitochondrial love-hate triangle. AmJ Physiol-Cell Physiol 287(4):C817-C833

158. Feissner RF, Skalska J, Gaum WE, Sheu S-S (2009) Crosstalk signaling between mitochondrial $\mathrm{Ca} 2+$ and ROS. Front Biosci: J Virtual Library 14:1197

159. Song I, Kim H, Lee S, Jeong S, Kim N, Ko K, Rhee B, Han J (2013) Mitochondrial modulation decreases the bortezomib-resistance in multiple myeloma cells. Int $\mathrm{J}$ Cancer 133(6):1357-1367

160. Zhan X, Yu W, Franqui-Machin R, Bates ML, Nadiminti K, Cao H, Amendt BA, Jethava Y, Frech I, Zhan F (2017) Alteration of mitochondrial biogenesis promotes disease progression in multiple myeloma. Oncotarget 8(67):111213

161. Marlein CR, Piddock RE, Mistry JJ, Zaitseva L, Hellmich C, Horton RH, Zhou Z, Auger MJ, Bowles KM, Rushworth SA (2019) CD38-driven mitochondrial trafficking promotes bioenergetic plasticity in multiple myeloma. Can Res 79(9):2285-2297

162. Jang JS, Li Y, Mitra AK, Bi L, Abyzov A, van Wijnen AJ, Baughn LB, Van Ness B, Rajkumar V, Kumar S (2019) Molecular signatures of multiple myeloma progression through single cell RNA-Seq. Blood Cancer J 9(1):1-10

163. Hoang PH, Cornish AJ, Chubb D, Jackson G, Kaiser M, Houlston RS (2020) Impact of mitochondrial DNA mutations in multiple myeloma. Blood Cancer J 10(5):1-4

164. Chauhan D, Li G, Podar K, Hideshima T, Mitsiades C, Schlossman R, Munshi N, Richardson P, Cotter FE, Anderson KC (2004) Targeting mitochondria to overcome conventional and bortezomib/proteasome inhibitor PS-341 resistance in multiple myeloma (MM) cells. Blood 104(8):2458-2466

165. Kazemi S, Mounir Z, Baltzis D, Raven JF, Wang S, Krishnamoorthy J-L, Pluquet O, Pelletier J, Koromilas AE (2007) A novel function of eIF $2 \alpha$ kinases as inducers of the phosphoinositide- 3 kinase signaling pathway. Mol Biol Cell 18(9):3635-3644

166. Jin J-K, Blackwood EA, Azizi K, Thuerauf DJ, Fahem AG, Hofmann C, Kaufman RJ, Doroudgar S, Glembotski CC (2017) ATF6 decreases myocardial ischemia/reperfusion damage and links ER stress and oxidative stress signaling pathways in the heart. Circ Res 120(5):862-875

167. Itoh K, Wakabayashi N, Katoh Y, Ishii T, Igarashi K, Engel JD, Yamamoto M (1999) Keap1 represses nuclear activation of antioxidant responsive elements by Nrf2 through binding to the amino-terminal Neh2 domain. Genes Dev 13(1):76-86

168. Loboda A, Damulewicz M, Pyza E, Jozkowicz A, Dulak J (2016) Role of Nrf2/HO-1 system in development, oxidative stress response and diseases: an evolutionarily conserved mechanism. Cell Mol Life Sci 73(17):3221-3247

169. Chanas SA, Jiang Q, McMAHON M, McWALTER GK, McLELLAN LI, Elcombe CR, Henderson CJ, Wolf CR, Moffat GJ, Itoh K (2002) Loss of the Nrf2 transcription factor causes a marked reduction in constitutive and inducible expression of the glutathione S-transferase Gsta1, Gsta2, Gstm1, Gstm2, Gstm3 and Gstm4 genes in the livers of male and female mice. Biochemical Journal 365(2):405-416

170. Dreger H, Westphal K, Weller A, Baumann G, Stangl V, Meiners S, Stangl K (2009) Nrf2-dependent upregulation of antioxidative enzymes: a novel pathway for proteasome inhibitor-mediated cardioprotection. Cardiovasc Res 83(2):354-361
171. Nioi P, McMahon M, Itoh K, Yamamoto M, Hayes JD (2003) Identification of a novel Nrf2-regulated antioxidant response element (ARE) in the mouse NAD (P) H: quinone oxidoreductase 1 gene: reassessment of the ARE consensus sequence. Biochemical Journal 374(2):337-348

172. Kovac S, Angelova PR, Holmström KM, Zhang Y, DinkovaKostova AT (1850) Abramov AY (2015) Nrf2 regulates ROS production by mitochondria and NADPH oxidase. Biochimica et Biophysica Acta (BBA)-Gen Subj 4:794-801

173. He X, Ma Q (2009) NRF2 cysteine residues are critical for oxidant/electrophile-sensing, Kelch-like ECH-associated protein1-dependent ubiquitination-proteasomal degradation, and transcription activation. Mol Pharmacol 76(6):1265-1278

174. Lo S-C, Hannink M (2008) PGAM5 tethers a ternary complex containing Keap1 and Nrf2 to mitochondria. Exp Cell Res 314(8):1789-1803

175. Kobayashi A, Kang M-I, Watai Y, Tong KI, Shibata T, Uchida K, Yamamoto M (2006) Oxidative and electrophilic stresses activate Nrf2 through inhibition of ubiquitination activity of Keap1. Mol Cell Biol 26(1):221-229

176. Huang H-C, Nguyen T, Pickett CB (2002) Phosphorylation of Nrf2 at Ser-40 by protein kinase $\mathrm{C}$ regulates antioxidant response element-mediated transcription. J Biol Chem 277(45):42769-42774

177. Ma Q (2013) Role of nrf2 in oxidative stress and toxicity. Annu Rev Pharmacol Toxicol 53:401-426

178. Cullinan SB, Zhang D, Hannink M, Arvisais E, Kaufman RJ, Diehl JA (2003) Nrf2 is a direct PERK substrate and effector of PERK-dependent cell survival. Mol Cell Biol 23(20):7198-7209

179. Lee S, Hur E-g, Ryoo I-g, Jung K-A, Kwak J, Kwak M-K (2012) Involvement of the Nrf2-proteasome pathway in the endoplasmic reticulum stress response in pancreatic $\beta$-cells. Toxicol Appl Pharmacol 264(3):431-438

180. Takahashi M, Higuchi M, Matsuki H, Yoshita M, Ohsawa T, Oie M, Fujii M (2013) Stress granules inhibit apoptosis by reducing reactive oxygen species production. Mol Cell Biol 33(4):815-829

181. Candé C, Vahsen N, Métivier D, Tourrière H, Chebli K, Garrido C, Tazi J, Kroemer G (2004) Regulation of cytoplasmic stress granules by apoptosis-inducing factor. J Cell Sci 117(19):4461-4468

182. Kedersha N, Chen S, Gilks N, Li W, Miller IJ, Stahl J, Anderson P (2002) Evidence that ternary complex (eIF2-GTP-tRNAi Met)-deficient preinitiation complexes are core constituents of mammalian stress granules. Mol Biol Cell 13(1):195-210

183. He CH, Gong P, Hu B, Stewart D, Choi ME, Choi AM, Alam J (2001) Identification of activating transcription factor 4 (ATF4) as an Nrf2-interacting protein Implication for heme oxygenase-1 gene regulation. J Biol Chem 276(24):20858-20865

184. Glover-Cutter KM, Lin S, Blackwell TK (2013) Integration of the unfolded protein and oxidative stress responses through SKN-1/ Nrf. PLoS Genet 9(9):e1003701

185. Yates MS, Tran QT, Dolan PM, Osburn WO, Shin S, McCulloch CC, Silkworth JB, Taguchi K, Yamamoto M, Williams CR (2009) Genetic versus chemoprotective activation of Nrf2 signaling: overlapping yet distinct gene expression profiles between Keap1 knockout and triterpenoid-treated mice. Carcinogenesis 30(6):1024-1031

186. Sun Y, Aziz AA, Bowles K, Rushworth S (2018) High NRF2 expression controls endoplasmic reticulum stress induced apoptosis in multiple myeloma. Cancer Lett 412:37-45

187. Wruck CJ, Streetz K, Pavic G, Götz ME, Tohidnezhad M, Brandenburg L-O, Varoga D, Eickelberg O, Herdegen T, Trautwein C (2011) Nrf2 induces interleukin-6 (IL-6) expression via an antioxidant response element within the IL-6 promoter. J Biol Chem 286(6):4493-4499 
188. Baranowska K, Misund K, Starheim KK, Holien T, Johansson I, Darvekar S, Buene G, Waage A, Bjørkøy G, Sundan A (2016) Hydroxychloroquine potentiates carfilzomib toxicity towards myeloma cells. Oncotarget 7(43):70845

189. Li B, Fu J, Chen P, Ge X, Li Y, Kuiatse I, Wang H, Wang H, Zhang X, Orlowski RZ (2015) The nuclear factor (erythroidderived 2)-like 2 and proteasome maturation protein axis mediate bortezomib resistance in multiple myeloma. J Biol Chem 290(50):29854-29868

190. Vaupel P, Mayer A, Höckel M (2004) Tumor hypoxia and malignant progression. Methods in enzymology, vol 381. Elsevier, Amsterdam, pp 335-354

191. Lévesque JP, Winkler IG, Hendy J, Williams B, Helwani F, Barbier V, Nowlan B, Nilsson SK (2007) Hematopoietic progenitor cell mobilization results in hypoxia with increased hypoxiainducible transcription factor- $1 \alpha$ and vascular endothelial growth factor A in bone marrow. Stem Cells 25(8):1954-1965

192. Kawano Y, Kikukawa Y, Fujiwara S, Wada N, Okuno Y, Mitsuya H, Hata H (2013) Hypoxia reduces CD138 expression and induces an immature and stem cell-like transcriptional program in myeloma cells. Int J Oncol 43(6):1809-1816

193. Muz B, De La Puente P, Azab F, Luderer M, Azab A (2014) Hypoxia promotes stem cell-like phenotype in multiple myeloma cells. Blood cancer J 4(12):e262-e262

194. Azab AK, Hu J, Quang P, Azab F, Pitsillides C, Awwad R, Thompson B, Maiso P, Sun JD, Hart CP (2012) Hypoxia promotes dissemination of multiple myeloma through acquisition of epithelial to mesenchymal transition-like features. Blood 119(24):5782-5794

195. Unruh A, Ressel A, Mohamed HG, Johnson RS, Nadrowitz R, Richter E, Katschinski DM, Wenger RH (2003) The hypoxiainducible factor- $1 \alpha$ is a negative factor for tumor therapy. Oncogene 22(21):3213-3220

196. Liu L, Wise DR, Diehl JA, Simon MC (2008) Hypoxic reactive oxygen species regulate the integrated stress response and cell survival. J Biol Chem 283(45):31153-31162

197. Wouters BG, Koritzinsky M (2008) Hypoxia signalling through mTOR and the unfolded protein response in cancer. Nat Rev Cancer 8(11):851-864

198. Bi M, Naczki C, Koritzinsky M, Fels D, Blais J, Hu N, Harding H, Novoa I, Varia M, Raleigh J (2005) ER stress-regulated translation increases tolerance to extreme hypoxia and promotes tumor growth. The EMBO Journal 24(19):3470-3481

199. Koritzinsky M, Magagnin MG, van den Beucken T, Seigneuric R, Savelkouls K, Dostie J, Pyronnet S, Kaufman RJ, Weppler SA, Voncken JW (2006) Gene expression during acute and prolonged hypoxia is regulated by distinct mechanisms of translational control. The EMBO Journal 25(5):1114-1125

200. Koumenis C, Naczki C, Koritzinsky M, Rastani S, Diehl A, Sonenberg N, Koromilas A, Wouters BG (2002) Regulation of protein synthesis by hypoxia via activation of the endoplasmic reticulum kinase PERK and phosphorylation of the translation initiation factor eIF2 $\alpha$. Mol Cell Biol 22(21):7405-7416

201. Rouschop KM, Dubois LJ, Keulers TG, van den Beucken T, Lambin P, Bussink J, van der Kogel AJ, Koritzinsky M, Wouters BG (2013) PERK/eIF2 $\alpha$ signaling protects therapy resistant hypoxic cells through induction of glutathione synthesis and protection against ROS. Proc Natl Acad Sci 110(12):4622-4627

202. Pereira ER, Frudd K, Awad W, Hendershot LM (2014) Endoplasmic reticulum (ER) stress and hypoxia response pathways interact to potentiate hypoxia-inducible factor 1 (HIF-1) transcriptional activity on targets like vascular endothelial growth factor (VEGF). J Biol Chem 289(6):3352-3364

203. Ivanova IG, Park CV, Yemm AI, Kenneth NS (2018) PERK/ eIF2 $\alpha$ signaling inhibits HIF-induced gene expression during the unfolded protein response via YB1-dependent regulation of HIF1 $\alpha$ translation. Nucleic Acids Res 46(8):3878-3890

204. Zhu K, Chan W, Heymach J, Wilkinson M, McConkey DJ (2009) Control of HIF-1 $\alpha$ Expression by eIF2 $\alpha$ Phosphorylation-Mediated Translational Repression. Can Res 69(5):1836-1843

205. Bartoszewska S, Collawn JF (2020) Unfolded protein response (UPR) integrated signaling networks determine cell fate during hypoxia. Cell Mol Biol Lett 25(1):1-20

206. Chen X, Iliopoulos D, Zhang Q, Tang Q, Greenblatt MB, Hatziapostolou M, Lim E, Tam WL, Ni M, Chen Y (2014) XBP1 promotes triple-negative breast cancer by controlling the HIF1 $\alpha$ pathway. Nature 508(7494):103-107

207. Romero-Ramirez L, Cao H, Nelson D, Hammond E, Lee A-H, Yoshida H, Mori K, Glimcher LH, Denko NC, Giaccia AJ (2004) $\mathrm{XBP} 1$ is essential for survival under hypoxic conditions and is required for tumor growth. Can Res 64(17):5943-5947

208. Delbrel E, Soumare A, Naguez A, Label R, Bernard O, Bruhat A, Fafournoux P, Tremblais G, Marchant D, Gille T (2018) HIF-1 $\alpha$ triggers ER stress and CHOP-mediated apoptosis in alveolar epithelial cells, a key event in pulmonary fibrosis. Scientific reports $8(1): 1-14$

209. Hillary RF, FitzGerald U (2018) A lifetime of stress: ATF6 in development and homeostasis. J Biomed Sci 25(1):48

210. Harris AL (2002) Hypoxia-a key regulatory factor in tumour growth. Nat Rev Cancer 2(1):38-47

211. Semenza GL (2012) Hypoxia-inducible factors in physiology and medicine. Cell 148(3):399-408

212. Movafagh S, Crook S, Vo K (2015) Regulation of hypoxia-inducible factor-1a by reactive oxygen species: new developments in an old debate. J Cell Biochem 116(5):696-703

213. Colla S, Storti P, Donofrio G, Todoerti K, Bolzoni M, Lazzaretti M, Abeltino M, Ippolito L, Neri A, Ribatti D (2010) Low bone marrow oxygen tension and hypoxia-inducible factor- $1 \alpha$ overexpression characterize patients with multiple myeloma: role on the transcriptional and proangiogenic profiles of CD138+ cells. Leukemia 24(11):1967-1970

214. Martin S, Diamond P, Gronthos S, Peet D, Zannettino A (2011) The emerging role of hypoxia, HIF-1 and HIF-2 in multiple myeloma. Leukemia 25(10):1533-1542

215. Tsubaki M, Takeda T, Tomonari Y, Koumoto Y-i, Imano M, Satou T, Nishida S (2019) Overexpression of HIF-1 $\alpha$ contributes to melphalan resistance in multiple myeloma cells by activation of ERK1/2, Akt, and NF-кB. Lab Invest 99(1):72-84

216. Umezu T, Tadokoro H, Azuma K, Yoshizawa S, Ohyashiki K, Ohyashiki JH (2014) Exosomal miR-135b shed from hypoxic multiple myeloma cells enhances angiogenesis by targeting factor-inhibiting HIF-1. Blood, The J Am Soc Hematol 124(25):3748-3757

217. Raninga PV, Di Trapani G, Vuckovic S, Bhatia M, Tonissen KF (2015) Inhibition of thioredoxin 1 leads to apoptosis in drugresistant multiple myeloma. Oncotarget 6(17):15410

218. Raninga PV, Di Trapani G, Vuckovic S, Tonissen KF (2016) TrxR1 inhibition overcomes both hypoxia-induced and acquired bortezomib resistance in multiple myeloma through NF-к $\beta$ inhibition. Cell Cycle 15(4):559-572

219. Murray MY, Zaitseva L, Auger MJ, Craig JI, MacEwan DJ, Rushworth SA, Bowles KM (2015) Ibrutinib inhibits BTK-driven NF- $\mathrm{\kappa B}$ p65 activity to overcome bortezomib-resistance in multiple myeloma. Cell Cycle 14(14):2367-2375

220. Tsubaki M, Takeda T, Ogawa N, Sakamoto K, Shimaoka H, Fujita A, Itoh T, Imano M, Ishizaka T, Satou T (2015) Overexpression of survivin via activation of ERK1/2, Akt, and NF- $\mathrm{KB}$ plays a central role in vincristine resistance in multiple myeloma cells. Leuk Res 39(4):445-452

221. Darling NJ (1843) Cook SJ (2014) The role of MAPK signalling pathways in the response to endoplasmic reticulum 
stress. Biochimica et Biophysica Acta (BBA)-Mol Cell Res 10:2150-2163

222. Gunter T, Buntinas L, Sparagna G, Eliseev R, Gunter K (2000) Mitochondrial calcium transport: mechanisms and functions. Cell Calcium 28(5-6):285-296

223. Higo T, Hattori M, Nakamura T, Natsume T, Michikawa T, Mikoshiba K (2005) Subtype-specific and ER lumenal environmentdependent regulation of inositol 1, 4, 5-trisphosphate receptor type 1 by ERp44. Cell 120(1):85-98

224. Roderick HL, Lechleiter JD, Camacho P (2000) Cytosolic phosphorylation of calnexin controls intracellular $\mathrm{Ca} 2+$ oscillations via an interaction with SERCA2b. The J Cell Biol 149(6): 1235-1248

225. Verfaillie T, Rubio N, Garg A, Bultynck G, Rizzuto R, Decuypere J, Piette J, Linehan C, Gupta S, Samali A (2012) PERK is required at the ER-mitochondrial contact sites to convey apoptosis after ROS-based ER stress. Cell Death Differ 19(11):1880-1891

226. Chami M, Oulès B, Szabadkai G, Tacine R, Rizzuto R, Paterlini-Bréchot P (2008) Role of SERCA1 truncated isoform in the proapoptotic calcium transfer from ER to mitochondria during ER stress. Mol Cell 32(5):641-651

227. Hayashi T, Su T-P (2007) Sigma-1 receptor chaperones at the ER-mitochondrion interface regulate $\mathrm{Ca} 2+$ signaling and cell survival. Cell 131(3):596-610

228. Mori T, Hayashi T, Hayashi E, Su T-P (2013) Sigma-1 receptor chaperone at the ER-mitochondrion interface mediates the mitochondrion-ER-nucleus signaling for cellular survival. PLoS ONE 8(10):e76941

229. Fransen M, Lismont C, Walton P (2017) The peroxisome-mitochondria connection: how and why? Int J Mol Sci 18(6):1126

230. Shai N, Schuldiner M (1863) Zalckvar E (2016) No peroxisome is an island-peroxisome contact sites. Biochimica et Biophysica Acta (BBA)-Mol Cell Res 5:1061-1069

231. Torres SE, Gallagher CM, Plate L, Gupta M, Liem CR, Guo X, Tian R, Stroud RM, Kampmann M, Weissman JS (2019) Ceapins block the unfolded protein response sensor ATF6 $\alpha$ by inducing a neomorphic inter-organelle tether. Elife 8:e46595

232. Morciano G, Marchi S, Morganti C, Sbano L, Bittremieux M, Kerkhofs M, Corricelli M, Danese A, Karkucinska-Wieckowska A, Wieckowski MR (2018) Role of mitochondria-associated ER membranes in calcium regulation in cancer-specific settings. Neoplasia 20(5):510-523

233. Chiu W-T, Chang H-A, Lin Y-H, Lin Y-S, Chang H-T, Lin H-H, Huang S-C, Tang M-J, Shen M-R (2018) Bcl-2 regulates storeoperated Ca 2+ entry to modulate ER stress-induced apoptosis. Cell Death Discov 4(1):1-14

234. Liu Z, Wild C, Ding Y, Ye N, Chen H, Wold EA, Zhou J (2016) $\mathrm{BH} 4$ domain of Bcl-2 as a novel target for cancer therapy. Drug Discov Today 21(6):989-996

235. Kerkhofs M, Vervloessem T, Bittremieux M, Bultynck G (2019) Recent advances in uncovering the mechanisms contributing to BIRD-2-induced cell death in B-cell cancer cells. Cell Death Dis 10(2):1-3

236. Bianchi G, Richardson PG, Anderson KC (2015) Promising therapies in multiple myeloma. Blood, The J Am Soc Hematol 126(3):300-310

237. Hideshima T, Ikeda H, Chauhan D, Okawa Y, Raje N, Podar K, Mitsiades C, Munshi NC, Richardson PG, Carrasco RD (2009) Bortezomib induces canonical nuclear factor- $\mathrm{\kappa B}$ activation in multiple myeloma cells. Blood 114(5):1046-1052

238. Maharjan S, Oku M, Tsuda M, Hoseki J, Sakai Y (2014) Mitochondrial impairment triggers cytosolic oxidative stress and cell death following proteasome inhibition. Scientific Reports 4:5896
239. Hetz C, Chevet E, Harding HP (2013) Targeting the unfolded protein response in disease. Nat Rev Drug Discov 12(9):703-719

240. Lü S, Wang J (2013) The resistance mechanisms of proteasome inhibitor bortezomib. Biomarker Research 1(1):1-9

241. Bianchi G, Oliva L, Cascio P, Pengo N, Fontana F, Cerruti F, Orsi A, Pasqualetto E, Mezghrani A, Calbi V (2009) The proteasome load versus capacity balance determines apoptotic sensitivity of multiple myeloma cells to proteasome inhibition. Blood, The $\mathrm{J}$ Am Soc Hematol 113(13):3040-3049

242. Cenci S, Oliva L, Cerruti F, Milan E, Bianchi G, Raule M, Mezghrani A, Pasqualetto E, Sitia R, Cascio P (2012) Pivotal Advance: Protein synthesis modulates responsiveness of differentiating and malignant plasma cells to proteasome inhibitors. J Leukoc Biol 92(5):921-931

243. Schubert U, Anton LC, Gibbs J, Norbury CC, Yewdell JW, Bennink JR (2000) Rapid degradation of a large fraction of newly synthesized proteins by proteasomes. Nature 404(6779):770-774

244. Lee A-H, Iwakoshi NN, Anderson KC, Glimcher LH (2003) Proteasome inhibitors disrupt the unfolded protein response in myeloma cells. Proc Natl Acad Sci 100(17):9946-9951

245. Schröder M, Kaufman RJ (2005) The mammalian unfolded protein response. Annu Rev Biochem 74:739-789

246. Zhou J, Chng W-J (2019) Novel mechanism of drug resistance to proteasome inhibitors in multiple myeloma. World J Clin Oncol 10(9):303

247. Kuhn DJ, Berkova Z, Jones RJ, Woessner R, Bjorklund CC, Ma W, Davis RE, Lin P, Wang H, Madden TL (2012) Targeting the insulin-like growth factor-1 receptor to overcome bortezomib resistance in preclinical models of multiple myeloma. Blood, The J Am Soc Hematol 120(16):3260-3270

248. Markovina S, Callander NS, O’Connor SL, Kim J, Werndli JE, Raschko M, Leith CP, Kahl BS, Kim K, Miyamoto S (2008) Bortezomib-resistant nuclear factor- $\mathrm{\kappa B}$ activity in multiple myeloma cells. Mol Cancer Res 6(8):1356-1364

249. Nerini-Molteni S, Ferrarini M, Cozza S, Caligaris-Cappio F, Sitia R (2008) Redox homeostasis modulates the sensitivity of myeloma cells to bortezomib. Br J Haematol 141(4):494-503

250. Jagannathan S, Abdel-Malek M, Malek E, Vad N, Latif T, Anderson K, Driscoll J (2015) Pharmacologic screens reveal metformin that suppresses GRP78-dependent autophagy to enhance the antimyeloma effect of bortezomib. Leukemia 29(11):2184-2191

251. Manasanch EE, Orlowski RZ (2017) Proteasome inhibitors in cancer therapy. Nature reviews Clinical oncology 14(7):417

252. Wallington-Beddoe CT, Sobieraj-Teague M, Kuss BJ, Pitson SM (2018) Resistance to proteasome inhibitors and other targeted therapies in myeloma. Br J Haematol 182(1):11-28

253. Gao Y, Sartori DJ, Li C, Yu Q-C, Kushner JA, Simon MC, Diehl JA (2012) PERK is required in the adult pancreas and is essential for maintenance of glucose homeostasis. Mol Cell Biol 32(24):5129-5139

254. Zhang W, Feng D, Li Y, Iida K, McGrath B, Cavener DR (2006) PERK EIF2AK3 control of pancreatic $\beta$ cell differentiation and proliferation is required for postnatal glucose homeostasis. Cell Metab 4(6):491-497

255. Iwawaki T, Akai R, Kohno K (2010) IRE1 $\alpha$ disruption causes histological abnormality of exocrine tissues, increase of blood glucose level, and decrease of serum immunoglobulin level. PLoS ONE 5(9):e13052

256. Bahlis NJ, McCafferty-Grad J, Jordan-McMurry I, Neil J, Reis I, Kharfan-Dabaja M, Eckman J, Goodman M, Fernandez HF, Boise LH (2002) Feasibility and correlates of arsenic trioxide combined with ascorbic acid-mediated depletion of intracellular glutathione for the treatment of relapsed/refractory multiple myeloma. Clin Cancer Res 8(12):3658-3668

257. Liu J, Chen H, Miller DS, Saavedra JE, Keefer LK, Johnson DR, Klaassen CD, Waalkes MP (2001) Overexpression of glutathione 
S-transferase II and multidrug resistance transport proteins is associated with acquired tolerance to inorganic arsenic. Mol Pharmacol 60(2):302-309

258. Munshi N, Tricot G, Desikan R, Badros A, Zangari M, Toor A, Morris C, Anaissie E, Barlogie B (2002) Clinical activity of arsenic trioxide for the treatment of multiple myeloma. Leukemia 16(9):1835-1837

259. Salem K, McCormick ML, Wendlandt E, Zhan F, Goel A (2015) Copper-zinc superoxide dismutase-mediated redox regulation of bortezomib resistance in multiple myeloma. Redox Biology 4:23-33

260. Elchuri S, Oberley TD, Qi W, Eisenstein RS, Roberts LJ, Van Remmen H, Epstein CJ, Huang T-T (2005) CuZnSOD deficiency leads to persistent and widespread oxidative damage and hepatocarcinogenesis later in life. Oncogene 24(3):367-380

261. Turski ML, Brady DC, Kim HJ, Kim B-E, Nose Y, Counter CM, Winge DR, Thiele DJ (2012) A novel role for copper in Ras/mitogen-activated protein kinase signaling. Mol Cell Biol 32(7):1284-1295

262. Jin N, Zhu X, Cheng F, Zhang L (2018) Disulfiram/copper targets stem cell-like ALDH+ population of multiple myeloma by inhibition of ALDH1A1 and Hedgehog pathway. J Cell Biochem 119(8):6882-6893

263. Axten JM, Medina JR, Feng Y, Shu A, Romeril SP, Grant SW, Li WHH, Heerding DA, Minthorn E, Mencken T (2012) Discovery of 7-methyl-5-(1-\{[3-(trifluoromethyl) phenyl] acetyl $\}$-2, 3-dihydro-1 H-indol-5-yl)-7 H-pyrrolo [2, 3-d] pyrimidin-4-amine (GSK2606414), a potent and selective first-in-class inhibitor of protein kinase R (PKR)-like endoplasmic reticulum kinase (PERK). J Med Chem 55(16):7193-7207

264. Atkins C, Liu Q, Minthorn E, Zhang S-Y, Figueroa DJ, Moss K, Stanley TB, Sanders B, Goetz A, Gaul N (2013) Characterization of a novel PERK kinase inhibitor with antitumor and antiangiogenic activity. Can Res 73(6):1993-2002

265. Papandreou I, Denko NC, Olson M, Van Melckebeke H, Lust S, Tam A, Solow-Cordero DE, Bouley DM, Offner F, Niwa M (2011) Identification of an Ire1alpha endonuclease specific inhibitor with cytotoxic activity against human multiple myeloma. Blood 117(4):1311-1314

266. Ri M, Tashiro E, Oikawa D, Shinjo S, Tokuda M, Yokouchi Y, Narita T, Masaki A, Ito A, Ding J (2012) Identification of Toyocamycin, an agent cytotoxic for multiple myeloma cells, as a potent inhibitor of ER stress-induced XBP1 mRNA splicing. Blood Cancer J 2(7):e79-e79

267. Cross BC, Bond PJ, Sadowski PG, Jha BK, Zak J, Goodman JM, Silverman RH, Neubert TA, Baxendale IR, Ron D (2012) The molecular basis for selective inhibition of unconventional mRNA splicing by an IRE1-binding small molecule. Proc Natl Acad Sci 109(15):E869-E878

268. Parzych K, Saavedra-García P, Valbuena GN, Al-Sadah HA, Robinson ME, Penfold L, Kuzeva DM, Ruiz-Tellez A, Loaiza S, Holzmann V (2019) The coordinated action of VCP/p97 and GCN2 regulates cancer cell metabolism and proteostasis during nutrient limitation. Oncogene 38(17):3216-3231

269. Le Moigne R, Aftab BT, Djakovic S, Dhimolea E, Valle E, Murnane M, King EM, Soriano F, Menon M-K, Wu ZY (2017) The p97 inhibitor CB-5083 is a unique disrupter of protein homeostasis in models of multiple myeloma. Mol Cancer Ther 16(11):2375-2386

270. Nakaya A, Sagawa M, Muto A, Uchida H, Ikeda Y, Kizaki M (2011) The gold compound auranofin induces apoptosis of human multiple myeloma cells through both down-regulation of STAT3 and inhibition of NF- $\mathrm{KB}$ activity. Leuk Res 35(2):243-249

271. Kim C, Lee S-G, Yang WM, Arfuso F, Um J-Y, Kumar AP, Bian J, Sethi G, Ahn KS (2018) Formononetin-induced oxidative stress abrogates the activation of STAT3/5 signaling axis and suppresses the tumor growth in multiple myeloma preclinical model. Cancer Lett 431:123-141

272. Berenson JR, Matous J, Swift RA, Mapes R, Morrison B, Yeh HS (2007) A phase I/II study of arsenic trioxide/bortezomib/ascorbic acid combination therapy for the treatment of relapsed or refractory multiple myeloma. Clin Cancer Res 13(6):1762-1768

273. Wang W, Adachi M, Kawamura R, Sakamoto H, Hayashi T, Ishida T, Imai K, Shinomura Y (2006) Parthenolide-induced apoptosis in multiple myeloma cells involves reactive oxygen species generation and cell sensitivity depends on catalase activity. Apoptosis 11(12):2225

274. Seo S-K, Lee H-C, Woo S-H, Jin H-O, Yoo D-H, Lee S-J, An S, Choe T-B, Park M-J, Hong S-I (2007) Sulindac-derived reactive oxygen species induce apoptosis of human multiple myeloma cells via p38 mitogen activated protein kinase-induced mitochondrial dysfunction. Apoptosis 12(1):195

Publisher's Note Springer Nature remains neutral with regard to jurisdictional claims in published maps and institutional affiliations. 